\title{
RING KONTEKS MORITA SEBAGAI ORDER DALAM SUATU RING ARTIN SEDERHANA
}

\section{(A MORITA CONTEXT RING AS AN ORDER OF A SIMPLE ARTINIAN RING)}

\author{
NOVITA DAHOKLORY*, INDAH EMILIA WIJAYANTI, SUTOPO
}

\begin{abstract}
Abstrak. Suatu konteks Morita merupakan 6-tupel $M=(R, V, W, S, \alpha, \beta)$ dengan $R$ dan $S$ merupakan ring, $V$ merupakan suatu $(R, S)$ - bimodul, $W$ merupakan suatu $(S, R)$ - bimodul, $\alpha: V \otimes_{S} W \rightarrow R$ merupakan suatu homomorfisma $(R, R)$-bimodul dan $\beta: W \otimes_{R} V \rightarrow S$ merupakan homomorfisma $(S, S)$-bimodul . Dengan menggunakan sifat pada komponen-komponen penyusun $M$, suatu ring dapat dikonstruksikan yaitu $T=\left(\begin{array}{cc}R & V \\ W & S\end{array}\right)$ yang disebut sebagai ring konteks Morita. Dalam penelitian ini, ring $T$ diasumsikan sebagai ring Goldie prima. Dengan kata lain, ring konteks Morita $T$ merupakan order dalam suatu ring Artin sederhana $Q(T)=\left(\begin{array}{cc}Q(R) & Q(V) \\ Q(W) & Q(S)\end{array}\right)$. Selanjutnya, dikenal order dalam dalam suatu ring Artin sederhana yang lebih khusus yaitu order maksimal dan order Asano. Lebih lanjut, penelitian ini bertujuan untuk memberikan beberapa syarat perlu dan cukup ring konteks Morita $T$ merupakan order maksimal dan order Asano di ring $Q(T)$.

Kata-kata kunci: Konteks Morita, ring Goldie prima, order maksimal, order Asano.
\end{abstract}

Abstract. A Morita context is a 6-tuple $M=(R, V, W, S, \alpha, \beta)$ where $R$ and $S$ are rings, $V$ an $(R, S)$ - bimodule, $W$ an $(S, R)$ - bimodule, $\alpha: V \otimes_{S} W \rightarrow R$ an $(R, R)$ - bimodule homomorphism and $\beta: W \otimes_{R} V \rightarrow S$ an $(S, S)$ - bimodule homomorphism. By using the components properties of $M$, a ring can be constructed which is $T=\left(\begin{array}{cc}R & V \\ W & S\end{array}\right)$ and $T$ is called Morita context ring. In this study, ring $T$ will be assumed as a prime Goldie ring. In other words, the Morita context ring $T$ is an order in a simple Artinian ring $Q(T)=\left(\begin{array}{cc}Q(R) & Q(V) \\ Q(W) & Q(S)\end{array}\right)$. Moreover, we know there are two particular orders in a simple Artinian ring which are maximal order and Asano order. Furthermore. this study aims to give the necessary and sufficient conditions for the Morita context ring $T$ to be a maximal order and an Asano order in $\operatorname{ring} Q(T)$.

Keywords: Morita context, prime Goldie ring, maximal order, Asano order. 


\section{PENDAHULUAN}

Konteks Morita merupakan 6-tupel $M=(R, V, W, S, \alpha, \beta)$ dengan $R$ dan $S$ merupakan ring, $V$ merupakan $(R, S)$ - bimodul $W$ merupakan $(S, R)$ - bimodul, $\alpha: Q \otimes_{S} P \rightarrow R$ merupakan homomorfisma $(R, R)$-bimodul dan $\beta: P \otimes_{R} Q \rightarrow$ $S$ merupakan homomorfisma $(S, S)$-bimodul. Dengan menggunakan sifat pada komponen-komponen konteks Morita $M$, dapat dibentuk suatu ring yaitu

$$
T=\left(\begin{array}{cc}
R & V \\
W & S
\end{array}\right)
$$

yang disebut sebagai ring konteks Morita.

Dalam suatu ring konteks Morita $T=\left(\begin{array}{cc}R & V \\ W & S\end{array}\right)$, ring $R$ dan $S$ yang merupakan ring Goldie prima belum menjamin ring $T$ sebagai ring Goldie prima. Salah satu contohnya adalah $\operatorname{ring} T=\left(\begin{array}{ll}\mathbb{Z} & \mathbb{Z}_{2} \\ \mathbb{Z} & \mathbb{Z}\end{array}\right)$ dengan $\alpha=\beta=0$. Apabila diperhatikan, $T$ bukan merupakan ring prima. Oleh karena itu, diberikan syarat perlu dan cukup agar ring konteks Morita $T$ merupakan ring Goldie prima sebagaimana yang tercantum pada penelitian [2] dan [7]. Suatu ring $T$ merupakan ring Goldie prima jika dan hanya jika $T$ merupakan order dalam suatu ring Artin sederhana $Q(T)$ 6. Dalam penelitian ini, diasumsikan ring konteks Morita $T$ merupakan ring Goldie prima. Dengan kata lain, ring $T$ merupakan order dalam suatu ring Artin sederhana $Q(T)$.

Penelitian ini bertujuan untuk menyelidiki sifat-sifat yang berlaku dalam ring konteks Morita sebagai order dalam suatu ring Artin sederhana. Dalam penelitian ini, akan dijabarkan secara mendetail bukti - bukti dari sifat sifat yang berlaku dalam ring konteks Morita yang merupakan order dalam suatu ring Artin sederhana yang merujuk pada [5] dan [4]. Dalam penelitian ini juga akan diberikan beberapa contoh terkait dengan ring konteks Morita sebagai order dalam suatu ring Artin sederhana. Selanjutnya dikenal order dalam suatu ring Artin sederhana yang lebih khusus yaitu order maksimal dan order Asano. Lebih lanjut, akan diberikan beberapa syarat perlu dan cukup sedemikian sehingga ring konteks Morita $T$ merupakan order maksimal dan order Asano.

Konsep dasar mengenai teori order dapat merujuk pada [3] dan [1]. Pada penelitian ini, himpunan semua elemen reguler di dalam suatu ring $R$ dinotasikan dengan $C_{R}(0)$. 


\section{KONTEKS MORITA SEBAGAI ORDER}

Suatu ring $R$ disebut ring Goldie kanan apabila ring $R$ berdimensi seragam hingga sebagai $R$-modul kanan dan memenuhi kondisi rantai naik untuk annihilator kanan, dalam artian bahwa untuk setiap rantai naik annihilator-annihilator kanan di $R$ yaitu $\left\{A n n^{r}\left(A_{n}\right)\right\}_{n \in \mathbb{N}}$ dengan $A_{n} \subseteq R$ terdapat $n_{0} \in \mathbb{N}$ sedemikian hingga $A n n^{r}\left(A_{n}\right)=A n n^{r}\left(A_{n+1}\right)$ untuk setiap $n \geq n_{0}$. Dengan cara yang sama dapat didefinisikan ring Goldie kiri. Ring $R$ disebut ring Goldie kiri apabila $R$ berdimensi seragam hingga sebagai $R$-modul kiri dan memenuhi kondisi rantai naik annihilator kiri. Ring $R$ disebut ring Goldi apabila $R$ merupakan ring Goldie kanan sekaligus ring Goldie kiri.

Suatu ring $R$ disebut ring Goldie prima apabila ring $R$ merupakan ring Goldie dan ring prima. Diketahui juga bahwa suatu ring $R$ merupakan ring Goldie prima jika dan hanya jika $R$ merupakan suatu order dalam suatu ring Artin sederhana 6].

Diberikan ring konteks Morita $T=\left(\begin{array}{cc}R & V \\ W & S\end{array}\right)$ dengan $R$ dan $S$ merupakan ring, $V$ merupakan suatu $(R, S)$ - bimodul, $W$ merupakan suatu $(S, R)$ - bimodul, $\alpha: V \otimes_{S} W \rightarrow R$ merupakan suatu homomorfisma $(R, R)$-bimodul dan $\beta$ : $W \otimes_{R} V \rightarrow S$ merupakan homomorfisma $(S, S)$-bimodul. Dalam penelitian ini, $\alpha\left(v \otimes_{S} w\right)$ dinotasikan dengan $v w, \beta\left(w \otimes_{R} v\right)$ dinotasikan dengan $w v$ untuk setiap $v \in V$ dan $w \in W$. Lebih lanjut, $i m(\alpha)$ dinotasikan dengan $V W$ dan $i m(\beta)$ dinotasikan dengan $W V$.

Apabila kita merujuk pada penelitian [2] dan [7, maka diperlukan untuk melengkapkan suatu syarat perlu dan cukup sehingga konteks Morita $T$ merupakan ring Goldie prima yang tertulis dalam lemma berikut.

Lemma 2.1 [2], [7] Misalkan $T=\left(\begin{array}{cc}R & V \\ W & S\end{array}\right)$ merupakan ring konteks Morita. Ring $T$ merupakan ring Goldie prima jika dan hanya jika

(1) $R$ dan $S$ merupakan ring Goldie prima,

(2) $j i k a v W=0$ maka $v=0$,

(3) jika $w V=0$ maka $w=0$,

(4) $j i k a V s W=0$ maka $s=0$.

Bukti. Bukti merujuk pada penelitian [2] dan [7].

Diberikan ring konteks Morita $T=\left(\begin{array}{cc}R & V \\ W & S\end{array}\right)$. Lebih lanjut, merujuk pada [5], dengan mengasumsikan $V$ sebagai $(R, S)$-bimodul yang bebas-torsi dan $W$ sebagai $(S, R)$-bimodul yang bebas-torsi, dikonstruksikan ring hasil bagi dari $T$ yaitu sebagai berikut: 


$$
Q(T)=\left(\begin{array}{cc}
Q(R) & Q(V) \\
Q(W) & Q(S)
\end{array}\right)
$$

dengan $Q(R)$ merupakan ring hasil bagi $R, Q(S)$ merupakan ring hasil bagi $S$, $Q(V)$ merupakan modul hasil bagi $V$ yaitu $Q(V)=Q(R) V=V Q(S)$ dan $Q(W)$ merupakan modul hasil bagi $W$ yaitu $Q(W)=Q(S) W=W Q(R)$ dengan $Q(R) V=$ $Q(R) \otimes_{R} V, V Q(S)=V \otimes_{S} Q(S), Q(S) W=Q(S) \otimes_{S} W, \operatorname{dan} W Q(R)=W \otimes_{R} Q(R)$ . Selanjutnya dalam penelitian ini ring $T$ dipandang sebagai order dalam suatu ring Artin sederhana $Q(T)$.

Berikut akan diberikan contoh ring konteks Morita sebagai order dalam suatu ring Artin sederhana yang mengacu pada lemma 2.1.

Contoh 2.2 (1) Ring konteks Morita $T=\left(\begin{array}{ll}\mathbb{Z} & 2 \mathbb{Z} \\ \mathbb{Z} & \mathbb{Z}\end{array}\right)$ dengan $\alpha$ dan $\beta$ merupakan operasi perkalian di ring $\mathbb{Z}$ merupakan order di $\operatorname{ring} Q(T)=\left(\begin{array}{ll}\mathbb{Q} & \mathbb{Q} \\ \mathbb{Q} & \mathbb{Q}\end{array}\right)$.

(2) Ring konteks Morita $T=\left(\begin{array}{ll}\mathbb{Z}[x] & \mathbb{Z}[x] \\ \mathbb{Z}[x] & \mathbb{Z}[x]\end{array}\right)$ dengan $\alpha$ dan $\beta$ merupakan operasi perkalian di ring $\mathbb{Z}[x]$ merupakan order di ring $Q(T)=\left(\begin{array}{ll}\mathbb{Q}[x] & \mathbb{Q}[x] \\ \mathbb{Q}[x] & \mathbb{Q}[x]\end{array}\right)$.

Misalkan $T$ merupakan order dalam suatu ring $Q(T)$. Diketahui bahwa ring $Q(T)$ dapat dipandang sebagai modul atas $\operatorname{ring} T$. Suatu $T$-submodul kanan $I$ di $Q(T)$ disebut $T$-ideal fraksional kanan apabila terdapat $c \in C_{T}(0)$ sedemikian hingga $c I \subseteq R$ dan $I$ memuat suatu elemen reguler di $T$. Suatu $T$-submodul kiri $I$ di $Q(T)$ disebut $T$-ideal fraksional kiri terdapat terdapat $c \in C_{T}(0)$ sedemikian hingga $I c \subseteq T$ dan $I$ memuat suatu elemen reguler di $T$. Suatu $T$-submodul $I$ di $Q(T)$ disebut $T$-ideal apabila $I$ merupakan $T$-ideal fraksional kiri sekaligus $T$-ideal fraksional kanan. $I$ disebut $T$-ideal integral apabila $I$ merupakan $T$-ideal dan $I \subseteq T$. Diketahui bahwa apabila suatu himpunan $I \subseteq Q(T)$ memuat suatu elemen reguler ekuivalen dengan $I Q(T)=Q(T) I=Q(T)$ (Proposition 3.1.1, [6]).

Sebagaimana pada teori order, hubungan antara modul $V$ dan modul hasil baginya yaitu $Q(V)$ dan modul $W$ dan modul hasil baginya yaitu $Q(W)$ memotivasi munculnya definisi-definisi berikut [4].

Definisi 2.3 Diberikan ring $T$ di ring $Q(T)$.

(1) Suatu $R$-submodul kiri $V^{\prime}$ di $Q(V)$ disebut $R$-modul fraksional kiri apabila terdapat $d \in C_{S}(0)$ sedemikian hingga $V^{\prime} d \subseteq V$ dan $Q(R) V^{\prime}=Q(V)$, $V^{\prime}$ disebut $S-$ modul fraksional kanan apabila terdapat $c \in C_{R}(0)$ sedemikian hingga $c V^{\prime} \subseteq V$ dan $V^{\prime} Q(S)=Q(V)$. Suatu $(R, S)$-bimodul kanan 
$V^{\prime}$ di $Q(V)$ disebut $(R, S)$ - modul fraksional apabila $V^{\prime}$ merupakan $R-$ modul fraksional kiri sekaligus $S$-modul fraksional kanan.

(2) Suatu S-submodul kiri $W^{\prime}$ di $Q(W)$ disebut $S$-modul fraksional kiri apabila terdapat $c \in C_{R}(0)$ sedemikian hingga $W^{\prime} c \subseteq W$ dan $Q(S) W^{\prime}=$ $Q(W)$. Suatu $R$-submodul kanan $W^{\prime}$ di $Q(W)$ disebut $R$-modul fraksional kanan apabila terdapat $d \in C_{S}(0)$ sedemikian hingga $d W^{\prime} \subseteq W$ dan $W^{\prime} Q(R)=Q(W)$. Suatu $(S, R)$-bimodul kanan $W^{\prime}$ di $Q(W)$ disebut $(S, R)$-modul fraksional di $Q(W)$ apabila $W^{\prime}$ merupakan $S$-modul fraksional kiri sekaligus $R$-modul fraksional kanan.

Berikut akan diberikan contoh suatu $(R, S)$-modul fraksional di $Q(V)$.

Contoh 2.4 (1) Diberikan $\operatorname{ring} T=\left(\begin{array}{cc}\mathbb{Z} & 2 \mathbb{Z} \\ \mathbb{Z} & \mathbb{Z}\end{array}\right)$ di $\operatorname{ring} Q(T)=\left(\begin{array}{ll}\mathbb{Q} & \mathbb{Q} \\ \mathbb{Q} & \mathbb{Q}\end{array}\right)$. Misalkan $A=\left(\begin{array}{ll}\frac{1}{2} \mathbb{Z} & \mathbb{Z} \\ \frac{1}{2} \mathbb{Z} & \mathbb{Z}\end{array}\right)$. Himpunan $V^{\prime}=\frac{1}{2} \mathbb{Z}$ di $\mathbb{Q}$ merupakan $(\mathbb{Z}, \mathbb{Z})$-modul fraksional di $\mathbb{Q}$, karena terdapat $4 \in$ sedemikian sehingga $4 V^{\prime}=4 \frac{1}{2} \mathbb{Z} \subseteq \mathbb{Z}$.

(2) Submodul nol di $Q(V)$ bukan merupakan $(S, R)$-modul fraksional. Hal ini disebabkan oleh $0 \cdot Q(R)=0$.

(3) Modul $V$ merupakan $(R, S)$-modul fraksional di $Q(V)$, karena $Q(R) V=$ $Q(V) V Q(S)$ dan terdapat $1_{R} \in C_{R}(0)$ dan $1_{S} \in C_{S}(0)$ sedemikan sehingga $1_{R} V \subseteq V$ dan $V 1_{S} \subseteq V$

Lemma 2.5 [5] Diketahui $T=\left(\begin{array}{cc}R & V \\ W & S\end{array}\right)$ merupakan order di ring $Q(T)=$ $\left(\begin{array}{cc}Q(R) & Q(V) \\ Q(W) & Q(S)\end{array}\right)$ dan suatu $(T, T)$-submodul $A=\left(\begin{array}{cc}I & V_{1} \\ W_{1} & J\end{array}\right)$ di $Q(T)$. Submodul A merupakan $T$-ideal jika dan hanya jika

(1) Himpunan $I$ merupakan $R$-ideal di $Q(R)$ dan himpunan $J$ merupakan $S-i d e a l$ di $Q(S)$;

(2) Himpunan $V_{1}$ merupakan $(R, S)$ - modul fraksional di $Q(V)$ dan himpunan $W_{1}$ merupakan $(S, R)-$ modul fraksional di $Q(W)$.

Bukti. $(\Rightarrow)$ Diketahui $A=\left(\begin{array}{cc}I & V_{1} \\ W_{1} & J\end{array}\right)$ merupakan $T$-ideal. Akan dibuktikan poin (1) dan (2).

Akan dibuktikan terlebih dahulu $I$ merupakan $R$-ideal fraksional kiri di $Q(R), V_{1}$ merupakan $R$-modul fraksional kiri di $Q(V), W_{1}$ merupakan $S$-modul fraksional kiri di $Q(W)$, dan $J$ merupakan $S$-ideal fraksional kiri di $Q(S)$. Karena $A=$ $\left(\begin{array}{cc}I & V_{1} \\ W_{1} & J\end{array}\right)$ merupakan $T$-ideal, berlaku 


$$
Q(T) A=\left(\begin{array}{cc}
Q(R) & Q(V) \\
Q(W) & Q(S)
\end{array}\right)\left(\begin{array}{cc}
I & V_{1} \\
W_{1} & J
\end{array}\right)=\left(\begin{array}{cc}
Q(R) & Q(V) \\
Q(W) & Q(S)
\end{array}\right)
$$

sehingga $Q(R) I=Q(R), Q(R) V_{1}=Q(V), Q(S) W_{1}=Q(W)$, dan $Q(S) J=$ $Q(S)$ (Lemma 1.2 pada [5]). Apabila diperhatikan, untuk setiap $\bar{t} \in Q(T)$ terdapat $c_{1} \in C_{R}(0), d_{1} \in C_{S}(0)$ sedemikian sehingga $\bar{t}\left(\begin{array}{cc}c_{1} & 0 \\ 0 & d_{1}\end{array}\right) \in T$. Selanjutnya diketahui bahwa $A$ merupakan $T$-ideal, yang artinya terdapat $\alpha \in C_{T}(0)$ sedemikian sehingga $A \alpha \subseteq T$. Apabila diperhatikan $\alpha^{-1} \in Q(T)$, berarti terdapat $c^{\prime} \in C_{R}(0), d^{\prime} \in C_{S}(0)$ sedemikian sehingga $\alpha^{-1}\left(\begin{array}{cc}c^{\prime} & 0 \\ 0 & d^{\prime}\end{array}\right)=t \in T$. Akibatnya $A\left(\begin{array}{cc}c^{\prime} & 0 \\ 0 & d^{\prime}\end{array}\right)=A \alpha t \subseteq T t \subseteq T$. Jadi, $\left(\begin{array}{cc}I & V_{1} \\ W_{1} & J\end{array}\right)\left(\begin{array}{cc}c^{\prime} & 0 \\ 0 & d^{\prime}\end{array}\right) \subseteq\left(\begin{array}{cc}R & V \\ W & S\end{array}\right)$ sehingga $I c^{\prime} \subseteq R, V_{1} d^{\prime} \subseteq V, W_{1} c^{\prime} \subseteq W$, dan $J d^{\prime} \subseteq S$. Terbukti, $I$ merupakan $R$-ideal fraksional kiri di $Q(R), W_{1}$ merupakan $S$-modul fraksional kiri di $Q(W), V_{1}$ merupakan $R$-ideal fraksional kiri di $Q(V)$, dan $J$ merupakan $S$-ideal fraksional kiri di $Q(S)$.

Untuk membuktikan $I$ merupakan $R$-ideal fraksional kanan di $Q(R), V_{1}$ merupakan $S$-modul fraksional kanan di $Q(V), W_{1}$ merupakan $R$-modul fraksional kanan di $Q(W)$, dan $J$ merupakan $S$-ideal fraksional kanan di $Q(S)$. Dengan cara yang sama yaitu menggunakan sifat $T$ sebagai $T$-ideal yaitu $A Q(T)=Q(T)$ dapat ditemukan $c^{\prime} \in C_{R}(0), d^{\prime} \in C_{S}(0)$ sedemikian sehingga $c^{\prime} I \subseteq R, c^{\prime} V_{1} \subseteq$ $V, d^{\prime} W_{1}^{\prime} \subseteq W$, dan $d^{\prime} J \subseteq S$. Jadi, $I$ merupakan $R$-ideal fraksional kanan di $Q(R)$, $V_{1}$ merupakan $S$-modul fraksional kanan di $Q(V), W_{1}$ merupakan $R$-modul fraksional kanan di $Q(W)$, dan $J$ merupakan $S$-ideal fraksional kanan di $Q(S)$. Jadi, terbukti poin (1) dan (2).

$(\Leftarrow)$ Diketahui bahwa $I$ merupakan $R$-ideal di $Q(R), J$ merupakan $S$-ideal di $Q(S), V_{1}$ merupakan $(R, S)$-modul fraksional di $Q(V)$, dan $W_{1}$ merupakan $(S, R)$ modul fraksional di $Q(W)$. Akan ditunjukkan $A$ merupakan $T$-ideal.

Karena $I$ merupakan $R$-ideal di $Q(R), J$ merupakan $S$-ideal di $Q(S), V_{1}$ merupakan $(R, S)$-modul fraksional di $Q(V)$, dan $W_{1}$ merupakan $(S, R)$-modul fraksional di $Q(W)$ maka terdapat $c, c^{\prime} \in C_{R}(0), d, d^{\prime} \in C_{S}(0)$ sedemikian hingga $c I \subseteq I, c^{\prime} V_{1} \subseteq V$ dan $d J \subseteq S, d^{\prime} W_{1} \subseteq W$. Karena $C_{R}(0)$ dan $C_{S}(0)$ merupakan himpunan penyebut, dapat diasumsikan $c=c^{\prime}$, dan $d=d^{\prime}$. Karena $V$ dan $W$ merupakan modul bebas-torsi, diperoleh $\left(\begin{array}{ll}c & 0 \\ 0 & d\end{array}\right)$ merupakan elemen reguler di $T$. Dengan demikian, diperoleh $\left(\begin{array}{cc}c & 0 \\ 0 & d\end{array}\right)\left(\begin{array}{cc}I & V_{1} \\ W_{1} & J\end{array}\right)=\left(\begin{array}{cc}c I & c V_{1} \\ d W_{1} & d J\end{array}\right) \subseteq\left(\begin{array}{cc}R & V \\ W & S\end{array}\right)$. 
Apabila diperhatikan, $\left(\begin{array}{cc}I & V_{1} \\ W_{1} & J\end{array}\right)\left(\begin{array}{cc}Q(R) & 0 \\ 0 & Q(R)\end{array}\right)=Q(T)$. Akibatnya berlaku $A Q(T)=Q(T)$. Jadi, $A$ merupakan $T$-ideal fraksional kanan.

Dengan analog yaitu memanfaatkan sifat $I$ merupakan $R$-ideal di $Q(R), J$ merupakan $S$-ideal di $Q(S), V_{1}$ merupakan $(R, S)$-modul fraksional di $Q(V)$, dan $W_{1}$ merupakan $(S, R)$-modul fraksional di $Q(W)$, terdapat suatu merupakan elemen reguler $\alpha=\left(\begin{array}{cc}c^{\prime} & 0 \\ 0 & d^{\prime}\end{array}\right)$ di $T$ sedemikian sehingga $A \alpha \subseteq T$. Selanjutnya, diperoleh juga bahwa $\left(\begin{array}{cc}Q(R) & 0 \\ 0 & Q(S)\end{array}\right)\left(\begin{array}{cc}I & V_{1} \\ W_{1} & J\end{array}\right)=Q(T)$. Akibatnya berlaku $Q(T) A=$ $Q(T)$. Jadi, $A$ merupakan $T$-ideal fraksional kiri.

Karena $A$ merupakan $T$-ideal fraksional kanan dan $T$-ideal fraksional kiri maka terbukti $A$ merupakan $T$-ideal.

Lemma 2.6 4] Diberikan order $T=\left(\begin{array}{cc}R & V \\ W & S\end{array}\right)$ di ring $Q(T)=\left(\begin{array}{cc}Q(R) & Q(V) \\ Q(W) & Q(S)\end{array}\right)$. Jika $V^{\prime}$ merupakan $(R, S)$-modul fraksional di $Q(V)$ dan $W^{\prime}$ merupakan $(S, R)-$ modul fraksional di $Q(W)$ maka

(1) $V^{\prime} W^{\prime}$ merupakan $R$-ideal di $Q(R)$ dan

(2) $W^{\prime} V^{\prime}$ merupakan $S-i d e a l$ di $Q(S)$.

Bukti. Diketahui $V^{\prime}$ merupakan $(R, S)$-modul fraksional di $Q(V)$ dan $W^{\prime}$ merupakan $(S, R)$-modul fraksional di $Q(W)$.

(1) Akan dibuktikan $V^{\prime} W^{\prime}$ merupakan $R$-ideal di $Q(R)$. Apabila diperhatikan, $V^{\prime} W^{\prime}$ merupakan $(R, R)$-bimodul di $Q(R)$. Karena $V^{\prime}$ merupakan $(R, S)-$ modul fraksional di $Q(V)$ dan $W^{\prime}$ merupakan $(S, R)$-modul fraksional di $Q(W)$, diperoleh $V^{\prime} W^{\prime} Q(R)=V^{\prime} Q(W)=V^{\prime} Q(S) W=Q(V) W^{\prime}=$ $Q(R) V W=Q(R)$. Dengan memanfaatkan $V^{\prime}$ merupakan $(R, S)$-modul fraksional di $Q(V)$ dan $W^{\prime}$ merupakan $(S, R)$-modul fraksional di $Q(W)$, terdapat $c_{1} \in C_{R}(0)$, dan $d_{1} \in C_{S}(0)$ sedemikian sehingga $W^{\prime} c_{1} \subseteq W, V^{\prime} d_{1}$ $\subseteq V$. Hal tersebut mengakibatkan,

$$
V^{\prime} W^{\prime} c_{1} V d_{1} W \subseteq V^{\prime} W V d_{1} W \subseteq V^{\prime} S d_{1} W \subseteq V^{\prime} d_{1} W \subseteq V W \subseteq R .
$$

Karena $d_{1} \in C_{S}(0)$, didapatkan $V^{\prime} d_{1} \neq 0$. Apabila diperhatikan $V^{\prime} d_{1} W$ merupakan ideal tak nol di $R$ sehingga $V^{\prime} d W$ memuat suatu elemen reguler di $R$, katakan $c^{\prime} \in V^{\prime} d_{1} W$. Oleh karena itu, berlaku $V^{\prime} W^{\prime} c_{1} c^{\prime} \subseteq$ $V^{\prime} W^{\prime} c_{1} V d_{1} W \subseteq R$ dengan $c_{1} c^{\prime} \in C_{R}(0)$. Sehingga dapat disimpulkan bahwa $V^{\prime} W^{\prime}$ merupakan $R$-ideal fraksional kiri.

Dengan cara analog yaitu dengan memanfaatkan sifat $V^{\prime}$ merupakan $(R, S)$ -modul fraksional di $Q(V)$ dan $W^{\prime}$ merupakan $(S, R)$-modul fraksional di 
$Q(W)$. Dapat ditemukan $c_{1} c^{\prime} \in C_{R}(0)$ sedemikian sehingga $c_{1} c^{\prime} V^{\prime} W^{\prime} \subseteq R$ dan $Q(R) V^{\prime} W^{\prime}=Q(R)$. Sehingga didapatkan $V^{\prime} W^{\prime}$ merupakan $R$-ideal fraksional kanan di $Q(R)$. Jadi, $V^{\prime} W^{\prime}$ merupakan $R$-ideal fraksional kiri sekaligus $R$-ideal fraksional kanan. Terbukti, $V^{\prime} W^{\prime}$ merupakan $R$-ideal di $Q(S)$.

(2) Akan dibuktikan $W^{\prime} V^{\prime}$ merupakan $S$-ideal di $Q(S)$. Analog dengan poin (1) yaitu dengan sifat $V^{\prime}$ merupakan $(R, S)$-modul fraksional di $Q(V)$ dan $W^{\prime}$ merupakan $(S, R)$-modul fraksional di $Q(W)$. Dapat ditemukan $d, d^{\prime} \in$ $C_{S}(0)$ sedemikian sehingga $d W^{\prime} V^{\prime} \subseteq S, W^{\prime} V^{\prime} d^{\prime} \subseteq S$ dan $W^{\prime} V^{\prime} Q(S)=$ $Q(S) W^{\prime} V^{\prime}=Q(S)$. Terbukti, $W^{\prime} V^{\prime}$ merupakan $S$-ideal di $Q(S)$.

Lemma 2.7 4] Diberikan order $T=\left(\begin{array}{cc}R & V \\ W & S\end{array}\right)$ di ring $Q(T)=\left(\begin{array}{cc}Q(R) & Q(V) \\ Q(W) & Q(S)\end{array}\right)$. Jika I merupakan $R$-ideal di $Q(R)$, J merupaka $S$-ideal di $Q(S)$, $V^{\prime}$ merupakan $(R, S)$-modul fraksional di $Q(V)$ dan $W^{\prime}$ merupakan $(S, R)$-modul fraksional di $Q(W)$ maka berlaku

(1) $I V^{\prime}$ dan $V^{\prime} J$ merupakan $(R, S)$-modul fraksional di $Q(V)$;

(2) $J W^{\prime}$ dan $W^{\prime} I$ merupakan $(S, R)$-modul fraksional di $Q(W)$.

Bukti. Diketahui $I$ merupakan $R$-ideal di $Q(R), J$ merupakan $S$-ideal di $Q(S)$, $V^{\prime}$ merupakan $(R, S)$-modul fraksional di $Q(V)$ dan $W^{\prime}$ merupakan $(S, R)$-modul fraksional di $Q(W)$. Akan dibuktikan poin (1) dan (2).

(1) Akan dibuktikan $I V^{\prime}$ dan $V^{\prime} J$ merupakan $(R, S)$-modul fraksional di $Q(V)$.

Pertama-tama akan dibuktikan terlebih dahulu untuk $I V^{\prime}$. Apabila diperhatikan bahwa $I V^{\prime}$ merupakan $(R, S)$-bimodul di $Q(V)$. Karena $I$ merupakan $R$-ideal di $Q(R)$ dan $V^{\prime}$ merupakan $(R, S)$-modul fraksional di $Q(V)$, maka terdapat $c, c^{\prime}, d \in C_{R}(0)$ dan $d^{\prime} \in C_{S}(0)$ sedemikian sehingga $c I \subset R, I c^{\prime} \subseteq R, d V^{\prime} \subseteq V$ dan $V^{\prime} d^{\prime} \subseteq V$. Jadi, diperoleh $d c I V^{\prime} \subseteq d R V^{\prime}=d V^{\prime} \subseteq V$ dan $I V^{\prime} Q(S)=I Q(R) V^{\prime}=Q(R) V^{\prime}=Q(V)$. Dengan demikian diperoleh, $I V^{\prime}$ merupakan $S$-modul fraksional kanan di $Q(V)$. Selanjutnya akan dibuktikan bahwa $I V^{\prime}$ merupakan $R$-modul fraksional kiri di $Q(R)$. Apabila diperhatikan dengan $I c^{\prime} \subseteq R$ dan $V^{\prime} d^{\prime} \subseteq V$ sehingga berlaku $\left(I V^{\prime}\right) d^{\prime} W c V \subseteq I V W c V \subseteq I R c V \subseteq R V=V$. Apabila diperhatikan juga bahwa $W c V$ merupakan ideal tak nol di $S$. Oleh karena itu, $W c V$ memuat elemen reguler di $S$, katakan $t \in W c V$. Akibatnya, terdapat $d^{\prime} t$ sedemikian sehingga $I V^{\prime} d^{\prime} t \subseteq\left(I V^{\prime}\right) d^{\prime} W c V \subseteq V$. Lebih lanjut diperoleh juga bahwa $Q(R) I V^{\prime}=Q(R) V^{\prime}=Q(V)$. Terbukti, $I V^{\prime}$ merupakan $R$-modul fraksional kiri di $Q(V)$. Karena $I V^{\prime}$ merupakan $R$-modul fraksional kiri dan $S$-modul fraksional kanan di $Q(V)$, terbukti $I V^{\prime}$ merupakan $(R, S)$-modul fraksional. 
Selanjutnya akan dibuktikan $V^{\prime} J$ merupakan $(R, S)$-modul fraksional. Dengan menggunakan analog pada pembuktian di atas yaitu memanfaatkan sifat $J$ sebagai $S$-ideal di $Q(S)$ dan $V^{\prime}$ sebagai $(R, S)$-modul fraksional. Sehingga berlaku $V^{\prime} J c_{1} d_{1} \subseteq V$ untuk suatu $c_{1}, d_{1} \in C_{S}(0)$ dan $V d W c V^{\prime} J \subseteq V d W$ dengan $c_{1} d_{1} \in C_{S}(0)$. Dengan memanfaatkan $V d W$ sebagai ideal tak nol di $R$, didapatkan terdapat $t \in C_{R}(0)$ sedemikian sehingga $t c V^{\prime} J \subseteq V d W c V^{\prime} J \subseteq V$ dengan $t c \in C_{R}(0)$. Jadi, diperoleh juga bahwa $V^{\prime} J Q(S)=V^{\prime} Q(S)=Q(V)$ dan $Q(R) V^{\prime} J=V^{\prime} Q(S)=Q(V)$. Terbukti, $V^{\prime} J$ merupakan $R$-modul fraksional kiri sekaligus $S$-modul fraksional kanan. Dengan kata lain, $V^{\prime} J$ merupakan $(R, S)$-modul fraksional.

(2) Akan dibuktikan $J W^{\prime}$ dan $W^{\prime} I$ merupakan $(S, R)$-modul fraksional di $Q(W)$.

Pertama-tama akan dibuktikan terlebih dahulu untuk $J W^{\prime}$. Apabila diperhatikan $J W^{\prime}$ merupakan $(S, R)$-bimodul di $Q(W)$.

Karena $J$ merupakan $S$-ideal di $Q(S)$ dan $W^{\prime}$ merupakan $(S, R)$-modul fraksional di $Q(V)$ maka terdapat $d, d^{\prime} \in C_{S}(0)$ sedemikian sehingga $d J \subseteq$ $S$ dan $d^{\prime} W^{\prime} \subseteq W$. Jadi, $d^{\prime} d J W^{\prime} \subseteq d^{\prime} S W^{\prime}=d W^{\prime} \subseteq W$ dan $J W^{\prime} Q(R)=$ $J Q(W)=J Q(S) W=Q(S) W=Q(W)$. Sehingga didapatkan $J W^{\prime}$ merupakan $R$-modul fraksional kanan di $Q(W)$.

Selanjutnya akan dibuktikan bahwa $J W^{\prime}$ merupakan $S$-modul fraksional kiri di $Q(W)$. Karena $J$ merupakan $S$-ideal di $Q(S)$ dan $W^{\prime}$ merupakan $(S, R)$-modul fraksional di $Q(W)$, diperoleh terdapat $c \in C_{R}(0)$ dan $d \in$ $C_{S}(0)$ sedemikian $W^{\prime} c \subseteq W$ dan sedemikian $J d \subseteq S$. Sehingga didapatkan $J W^{\prime} c V d W \subseteq J W V d W \subseteq W$. Karena $V d W$ ideal tak nol, maka terdapat $t \in C_{R}(0)$ dengan $t \in V d W$. Jadi, $J W^{\prime} c t \subseteq J W^{\prime} c V d W \subseteq W$ untuk suatu $c t \in C_{R}(0)$. Terbukti, $J W^{\prime}$ merupakan $S$-modul fraksional kiri di $Q(W)$. Karena $J W^{\prime}$ merupakan $S$-modul fraksional kiri dan $R$-modul fraksional kanan di $Q(W)$, maka terbukti $J W^{\prime}$ merupakan $(S, R)-$ modul fraksional di $Q(W)$.

Selanjutnya akan dibuktikan $W^{\prime} I$ merupakan $(S, R)$-modul fraksional di $Q(W)$. Dengan memanfaatkan sifat $I$ sebagai $R$-ideal di $Q(R)$ dan $W^{\prime}$ sebagai $(S, R)$-modul fraksional, didapatkan $W^{\prime} I Q(R)=W^{\prime} Q(R)=Q(W)$ dan $Q(S) W^{\prime} I=W^{\prime} Q(R) I=W^{\prime} Q(R)=Q(W)$. Berlaku juga bahwa $W^{\prime} I c_{1} d_{1} \subseteq W^{\prime}$ untuk suatu $c_{1}, d_{1} \in C_{R}(0)$ dan $W c V d^{\prime} W^{\prime} I \subseteq W$ untuk suatu $c \in C_{R}(0)$ dan $d^{\prime} \in C_{S}(0)$ dengan $I c_{1} \subseteq R, W^{\prime} d_{1} \subseteq W, c I \subseteq R$, dan $d W^{\prime} \subseteq W$. Oleh karena itu, $W^{\prime} I c_{1} d_{1} \subseteq W^{\prime}$ dan $t d^{\prime} W^{\prime} I$ untuk suatu eelemen reguler $t \in W c V$ dengan $c_{1} d_{1} \in C_{R}(0)$ dan $t d^{\prime} \in C_{S}(0)$. Jadi, 
$W^{\prime} I$ merupakan $R$-modul fraksional kanan di $Q(W)$ dan $S$-modul fraksional kiri di $Q(W)$. Terbukti, $W^{\prime} I$ merupakan $(S, R)$-modul fraksional di $Q(W)$.

Lemma 2.8 [4] Diberikan order $T=\left(\begin{array}{cc}R & V \\ W & S\end{array}\right)$ di ring $Q(T)=\left(\begin{array}{cc}Q(R) & Q(V) \\ Q(W) & Q(S)\end{array}\right)$.

(1) Jika I merupakan $R$-ideal di $Q(R)$ maka $\left(\begin{array}{cc}I & I V \\ W I & W I V\end{array}\right)$ merupakan $T$-ideal.

(2) Jika J merupakan $S$-ideal di $Q(S)$ maka $\left(\begin{array}{cc}V J W & V J \\ J W & J\end{array}\right)$ merupakan $T$-ideal.

Bukti. Pada bagian ini akan dibuktikan poin (1) dan poin (2). Diketahui bahwa $I$ merupakan $R$-ideal dan $J$ merupakan $S$-ideal. Menurut Lemma 2.7, didapatkan $I V, V J$ merupakan $(R, S)$-modul fraksional dan $W I, J W$ merupakan $(S, R)$-modul fraksional. Selanjutnya, berdasarkan Lemma 2.6, diperoleh $W I V$ merupakan $S$-ideal dan $V J W$ merupakan $R$-ideal. Dengan memanfaatkan Lemma 2.5, berlaku

$$
\left(\begin{array}{cc}
I & I V \\
W I & W I V
\end{array}\right) \operatorname{dan}\left(\begin{array}{cc}
V J W & V J \\
J W & J
\end{array}\right)
$$

merupakan $T$-ideal.

Suatu order $R$ di $\operatorname{ring} Q(R)$ disebut order maksimal apabila $O_{l}(I)=O_{r}(I)=R$ untuk setiap $I$ yang merupakan $R$-ideal di $Q(R)$ dengan $O_{l}(I)=\{q \in Q(R) \mid$ $q I \subseteq I\}$ dan $O_{r}(I)=\{q \in Q(R) \mid I q \subseteq I\}$ 3. Hal ini kemudian memotivasi definisi berikut 4 .

Definisi 2.9 Diberikan ring konteks Morita $T$ di ring $Q(T)$.

(1) $V$ disebut $(R, S)$ - modul maksimal di $Q(V)$ jika $O_{l}\left(V^{\prime}\right)=R \operatorname{dan} O_{r}\left(V^{\prime}\right)$ $=S$ untuk setiap $V^{\prime}$ yang merupakan $(R, S)$-modul fraksional integral di $Q(V)$ dengan $O_{l}\left(V^{\prime}\right)=\left\{q \in Q(R) \mid q V^{\prime} \subseteq V^{\prime}\right\}$ dan $O_{r}\left(V^{\prime}\right)=\left\{q^{\prime} \in\right.$ $Q(S) \mid V^{\prime} q^{\prime} \subseteq V^{\prime}$.

(2) $W$ disebut $(S, R)$-modul maksimal di $Q(W)$ jika $O_{l}\left(W^{\prime}\right)=S$ dan $O_{r}\left(W^{\prime}\right)=R$ untuk setiap $W^{\prime}$ yang merupakan $(S, R)$-modul fraksional di $Q(W)$ dengan $O_{l}\left(W^{\prime}\right)=\left\{q \in Q(S) \mid q W^{\prime} \subseteq W^{\prime}\right.$ dan $O_{r}\left(W^{\prime}\right)=\left\{q^{\prime} \in\right.$ $\left.Q(R) \mid W^{\prime} q^{\prime} \subseteq W^{\prime}\right\}$

Berikut akan diberikan contoh $(R, S)$-modul maksimal di $Q(V)$.

Contoh 2.10 Diberikan $\operatorname{ring} T=\left(\begin{array}{cc}\mathbb{Z} & 2 \mathbb{Z} \\ \mathbb{Z} & \mathbb{Z}\end{array}\right)$ di $\operatorname{ring} Q(T)=\left(\begin{array}{ll}\mathbb{Q} & \mathbb{Q} \\ \mathbb{Q} & \mathbb{Q}\end{array}\right)$. Apabila diperhatikan $\mathbb{Z}$ merupakan order maksimal, didapatkan $O_{l}\left(V^{\prime}\right)=\mathbb{Z}$ dan $O_{r}\left(V^{\prime}\right)=\mathbb{Z}$ untuk setiap $V^{\prime}$ yang merupakan $(R, S)$-modul fraksional di $\mathbb{Q}$. Jadi, $2 \mathbb{Z}$ merupakan $(\mathbb{Z}, \mathbb{Z})$-modul maksimal. 
Apabila diperhatikan $O_{r}\left(V^{\prime}\right)$ merupakan order di ring $Q(R)$ dan $O_{r}\left(V^{\prime}\right)$ merupakan order di ring $Q(R)$ untuk setiap $V^{\prime}$ yang merupakan $(R, S)$-modul fraksional integral di $Q(V)$. Diberikan order $R$ dan $S$ di dalam suatu ring $Q(R)$. Order $R$ dan $S$ di ring $Q(R)$ dikatakan ekuivalen apabila terdapat $a_{1}, a_{2}, b_{1}, b_{2} \in C_{R}(0)$ sedemikian sehingga $a_{1} R a_{2} \subseteq S$ dan $b_{1} S b_{2} \subseteq R[6$.

Lemma 2.11 [4] Diberikan order $T=\left(\begin{array}{cc}R & V \\ W & S\end{array}\right)$ diring $Q(T)=\left(\begin{array}{cc}Q(R) & Q(V) \\ Q(W) & Q(S)\end{array}\right)$.

(1) Jika $V^{\prime}$ merupakan $(R, S)$-modul fraksional di $Q(V)$ maka $O_{l}\left(V^{\prime}\right)$ ekuivalen dengan $R$ dan $O_{r}\left(V^{\prime}\right)$ ekuivalen dengan $S$;

(2) Jika $W^{\prime}$ merupakan $(S, R)$ - modul fraksional di $Q(W)$ maka $O_{l}\left(W^{\prime}\right)$ ekuivalen dengan $S$ dan $O_{r}\left(W^{\prime}\right)$ ekuivalen dengan $R$.

Bukti. (1) Diketahui bahwa $V^{\prime}$ merupakan $(R, S)$-modul fraksional di $Q(V)$ yang berarti terdapat $d \in C_{S}(0)$ sedemikian sehingga $V^{\prime} d \subseteq V$. Hal ini mengakibatkan $O_{l}\left(V^{\prime}\right) V^{\prime} d W \subseteq V W \subseteq R$. Karena $V^{\prime} d W$ merupakan ideal tak nol di $R$, diperoleh $V^{\prime} d W$ memuat elemen reguler di $R$, katakan $c \in C_{R}(0)$. Jadi, $O l\left(V^{\prime}\right) c \subseteq O l\left(V^{\prime}\right) V^{\prime} d W \subseteq R$. Apabila diperhatikan $R \subseteq O_{l}(R)$. Jadi, $1_{R} O l\left(V^{\prime}\right) c \subseteq R$ dan $1_{R} R 1_{R} \subseteq O_{l}\left(V^{\prime}\right)$. Terbukti, $O_{l}\left(V^{\prime}\right)$ ekuivalen dengan $R$.

Dengan memanfaatkan $V^{\prime}$ yang merupakan $(R, S)$-modul fraksional di $Q(V)$ yaitu terdapat $c^{\prime} \in C_{R}(0)$ dengan $c^{\prime} V \subseteq V$, dapat ditemukan suatu $d^{\prime} \in C_{S}(0)$ sehingga $\operatorname{Or}\left(V^{\prime}\right) d \subseteq S$. Dengan cara analog pada pembuktian di atas, dapat dibuktikan $O_{r}\left(V^{\prime}\right)$ ekuivalen dengan $S$.

(2) Diketahui bahwa $W^{\prime}$ merupakan $(S, R)$-modul fraksional di $Q(W)$, yang berarti terdapat $c \in C_{R}(0)$ sedemikian sehingga $W^{\prime} c \subseteq W$. Hal ini mengakibatkan $O_{l}\left(W^{\prime}\right) W^{\prime} c V \subseteq W^{\prime} c V \subseteq S$ dan $W^{\prime} c V$ memuat elemen reguler di $S$, katakan $d \in C_{S}(0)$. Jadi, $O l\left(W^{\prime}\right) d \subseteq O l\left(W^{\prime}\right) W^{\prime} c V \subseteq W^{\prime} c V \subseteq$ $W V \subseteq S$. Apabila diperhatikan $S \subseteq O_{l}\left(W^{\prime}\right)$. Jadi, $1_{R} O l\left(W^{\prime}\right) d \subseteq R$ dan $1_{S} S 1_{S} \subseteq O_{l}\left(W^{\prime}\right)$. Terbukti, $O_{l}\left(W^{\prime}\right)$ ekuivalen dengan $S$.

Dengan memanfaatkan $W^{\prime}$ yang merupakan $(S, R)$-modul fraksional di $Q(W)$ yaitu terdapat $d^{\prime} \in C_{S}(0)$ dengan $d^{\prime} W \subseteq W$, dapat ditemukan suatu $c^{\prime} \in C_{R}(0)$ sehingga $O r\left(W^{\prime}\right) d \subseteq R$. Dengan cara analog pada pembuktian di atas, dapat dibuktikan $O_{r}\left(W^{\prime}\right)$ ekuivalen dengan $R$.

Lemma 2.12 [4] Diberikan order $T=\left(\begin{array}{cc}R & V \\ W & S\end{array}\right)$ di ring $Q(T)=\left(\begin{array}{cc}Q(R) & Q(V) \\ Q(W) & Q(S)\end{array}\right)$. Ring $R$ merupakan order maksimal di $Q(R)$ dan ring $S$ merupakan order maksimal di $Q(S)$ jika dan hanya jika $V$ merupakan $(R, S)$-modul maksimal di $Q(V)$ dan $W$ merupakan $(S, R)$ - modul maksimal di $Q(W)$. 
Bukti. $\Rightarrow$ Diketahui ring $R$ merupakan order maksimal di $Q(R)$ dan ring $S$ merupakan order maksimal di $Q(S)$. Akan dibuktikan, $V$ merupakan $(R, S)$-modul maksimal di $Q(V)$ dan $W$ merupakan $(S, R)$-modul maksimal di $Q(W)$.

Pertama-tama akan dibuktikan $V$ merupakan $(R, S)$-modul maksimal di $Q(V)$. Diambil sebarang $V^{\prime}$ yang merupakan $(R, S)$-modul fraksional di $Q(V)$. Jelas bahwa $R \subseteq O_{l}\left(V^{\prime}\right)$ dan $S \subseteq O_{r}\left(V^{\prime}\right)$. Menurut Lemma 2.11, diperoleh $O_{l}\left(V^{\prime}\right)$ ekuivalen dengan $R$ dan $O_{r}\left(V^{\prime}\right)$ ekuivalen dengan $S$. Sehingga didapatkan $O_{l}\left(V^{\prime}\right)=R$ dan $O_{r}\left(V^{\prime}=S\right.$ (Proposition 5.1.4, 6] $)$. Jadi, terbukti $V$ merupakan $(R, S)$-modul maksimal di $Q(V)$.

Selanjutnya dibuktikan $W$ merupakan $(S, R)$-modul maksimal di $Q(W)$. Diambil sebarang $W^{\prime}$ yang merupakan $(S, R)$-modul fraksional di $Q(W)$. Jelas bahwa $R \subseteq O_{l}\left(V^{\prime}\right)$ dan $S \subseteq O_{r}\left(V^{\prime}\right)$. Menurut Lemma 2.11 didapatkan $O_{l}\left(W^{\prime}\right)$ ekuivalen dengan $S$ dan $O_{r}\left(W^{\prime}\right)$ ekuivalen dengan $R$. Sehingga diperoleh $O_{l}\left(W^{\prime}\right)=S$ dan $O_{r}\left(W^{\prime}\right)=R$ (Proposition 5.1.4, [6]). Akibatnya, $W$ merupakan $(S, R)$-modul maksimal di $Q(W)$.

$\Leftarrow$ Diketahui $V$ merupakan $(R, S)$-modul maksimal di $Q(V)$ dan $W$ merupakan $(S, R)$-modul maksimal di $Q(W)$. Akan dibuktikan Ring $R$ merupakan order maksimal di $Q(R)$ dan ring $S$ merupakan order maksimal di $Q(S)$.

Pertama-tama akan dibuktikan $R$ merupakan order maksimal di $Q(R)$. Diambil sebarang $R$-ideal integral $I$ di $Q(R)$. Jelas bahwa $R \subseteq O_{l}(I)$ dan $R \subseteq O_{r}(I)$, sehingga hanya perlu ditunjukkan $O_{l}(I) \subseteq R$ dan $O_{r}(I) \subseteq R$. Untuk setiap $q \in O_{l}(I)$ yaitu $q I \subseteq I$, sehingga berlaku $q I V \subseteq I V$ dan $q \in O_{l}(I V)=R$. Karena $I V$ merupakan $(R, S)$-modul maksimal di $Q(V)$, didapatkan $O_{l}(I V)=R$. Selanjutnya diambil sebarang $q \in O_{r}(I)$, yang berarti $I q \subseteq I$. Jadi, $W I q \subseteq W I$. Apabila diperhatikan $W I$ merupakan $(S, R)$-modul maksimal di $Q(W)$, diperoleh $q \in O_{r}(W I)=R$. Jadi, diperoleh $O_{r}(I)=R$ (Proposisi 2.1.1, [3]). Dengan demikian, diperoleh $R$ merupakan order maksimal.

Untuk membuktikan $S$ merupakan order maksimal di $Q(S)$, dapat ditunjukkan dengan mengambil sebarang $S$-ideal $J$ di $Q(S)$ yang termuat di $S$. Dengan memanfaatkan $J W$ merupakan $(S, R)$-modul maksimal di $Q(W)$ dan $V J$ merupakan $(R, S)$-modul fraksional di $Q(V)$, dapat ditunjukkan bahwa $O_{r}(J)=S$ dan $O_{l}(J)=S$. Dengan demikian, diperoleh $R$ merupakan order maksimal.

Diberikan order $R$ di ring $Q(R)$. Untuk sebarang $X \subseteq Q(R)$, didefinisikan $(R: X)_{l}=\{\bar{x} \in Q(R) \mid \bar{x} X \subseteq R\}$ dan $(R: X)_{r}=\{\bar{x} \in Q(R) \mid X \bar{x} \subseteq R\}$. Hal ini kemudian memotivasi pendefinisian himpunan berikut. Misalkan $V^{\prime} \subseteq Q(V)$ dan $W^{\prime} \subseteq Q(W)$, maka dapat didefinisikan himpunan-himpunan dalam $Q(V)$ dan $Q(W)$ sebagai berikut:

$$
\left(R: V^{\prime}\right)_{r}=\left\{\bar{w} \in Q(W) \mid V^{\prime} \bar{w} \subseteq R\right\}, \quad\left(S: V^{\prime}\right)_{l}=\left\{\bar{w} \in Q(W) \mid \bar{w} V^{\prime} \subseteq S\right\},
$$




$$
\left(S: W^{\prime}\right)_{r}=\{\bar{v} \in Q(V) \mid W \bar{v} \subseteq S\}, \quad\left(R: W^{\prime}\right)_{l}=\left\{\bar{v} \in Q(V) \mid \bar{v} W^{\prime} \subseteq R\right\} .
$$

Lemma 2.13 4] Diberikan order $T=\left(\begin{array}{cc}R & V \\ W & S\end{array}\right)$ di ring $Q(T)=\left(\begin{array}{cc}Q(R) & Q(V) \\ Q(W) & Q(S)\end{array}\right)$.

(1) (a) Jika $V^{\prime}$ merupakan $S$-modul fraksional kanan di $Q(V)$ maka $\left(S: V^{\prime}\right)_{l}$ merupakan $S$-modul fraksional kiri di $Q(W)$;

(b) Jika $V^{\prime}$ merupakan $R$-modul fraksional kiri di $Q(V)$ maka $\left(R: V^{\prime}\right)_{r}$ merupakan $R$-modul fraksional kanan di $Q(W)$.

(2) (a) Jika $W^{\prime}$ merupakan $R$-modul fraksional kanan di $Q(W)$ maka $(R$ : $\left.W^{\prime}\right)_{l}$ merupakan $R$-modul fraksional kiri di $Q(V)$;

(b) Jika $W^{\prime}$ merupakan $S$-modul fraksional kiri di $Q(W)$ maka $\left(S: W^{\prime}\right)_{r}$ merupakan $S$-modul fraksional kanan di $Q(V)$.

Bukti. (1) (a) Diketahui $V^{\prime}$ merupakan $S$-modul fraksional kanan di $Q(V)$, maka terdapat elemen reguler $c \in C_{R}(0)$ sedemikian hingga $c V^{\prime} \subseteq V$. Selanjutnya akan dibuktikan $\left(S: V^{\prime}\right)_{l}$ merupakan $S$-modul fraksional kiri di $Q(W)$. Apabila diperhatikan $W \subseteq\left(S: c V^{\prime}\right)_{l}=(S$ : $\left.V^{\prime}\right)_{l} c^{-1}$. Jadi, $W c \subseteq\left(S: V^{\prime}\right)_{l}$. Dari sini, diperoleh $Q(W)=W Q(R)=$ $W Q(R) c=Q(S) W c \subseteq Q(S)\left(S: V^{\prime}\right)_{l} \subseteq Q(W)$ sehingga $Q(S)(S:$ $\left.V^{\prime}\right)_{l}=Q(W)$. Menurut Lemma 2.6, $V^{\prime} W$ merupakan $R$-ideal di $Q(R)$, sehingga $V^{\prime} W$ memuat elemen reguler katakan $t \in C_{R}(0)$. Sehingga didapatkan $\left(S: V^{\prime}\right)_{l} t \subseteq\left(S: V^{\prime}\right)_{l} V^{\prime} W \subseteq S W=W$. Dengan demikian diperoleh $\left(S: V^{\prime}\right)_{l}$ merupakan $S$-modul fraksional kiri di $Q(W)$.

(b) Diketahui $V^{\prime}$ merupakan $R$-modul fraksional kiri di $Q(V)$ yaitu terdapat elemen reguler $d \in C_{S}(0)$ sedemikian hingga $V^{\prime} d \subseteq V$. Dengan menggunakan $V^{\prime} d \subseteq V$, dapat dibuktikan bahwa $\left(R: V^{\prime}\right)_{r} Q(R)=$ $Q(W)$. Dengan memanfaatkan $W V^{\prime}$ sebagai $S$-ideal, dapat ditemukan suatu elemen reguler $t \in W V^{\prime}$ sehingga $t\left(R: V^{\prime}\right)_{r} \subseteq W V^{\prime}(R$ : $\left.V^{\prime}\right)_{r} \subseteq W$. Terbukti, $\left(R: V^{\prime}\right)_{r}$ merupakan $R$-modul fraksional kanan.

(2) (a) Diketahui $W^{\prime}$ merupakan $R$-modul fraksional kanan di $Q(W)$. Hal tersebut berarti terdapat elemen reguler $d \in C_{S}(0)$ sedemikian hingga $d W^{\prime} \subseteq W$. Selanjutnya akan dibuktikan $\left(R: W^{\prime}\right)_{l}$ merupakan $R-$ modul fraksional kiri di $Q(V)$. Apabila diperhatikan $V \subseteq\left(R: d W^{\prime}\right)_{l}=$ $\left(R: W^{\prime}\right)_{l} d^{-1}$. Jadi, $V d \subseteq\left(R: W^{\prime}\right)_{l}$. Dari sini, diperoleh $Q(V)=$ $V Q(S)=V Q(S) d=Q(R) V d \subseteq Q(R)\left(R: W^{\prime}\right)_{l} \subseteq Q(V)$. Sehingga didapatkan $Q(R)\left(R: W^{\prime}\right)_{l}=Q(V)$. Menurut Lemma 2.6, $W^{\prime} V$ merupakan $S$-ideal di $Q(S)$, sehingga $W^{\prime} V$ memuat elemen reguler katakan $t \in C_{S}(0)$. Jadi, didapatkan, $\left(R: W^{\prime}\right)_{l} t \subseteq\left(R: W^{\prime}\right)_{l} W^{\prime} V \subseteq$ $R V=V$. Dengan demikian diperoleh $\left(R: W^{\prime}\right)_{l}$ merupakan $R$-modul fraksional kiri di $Q(V)$. 
(b) Diketahui $W^{\prime}$ merupakan $S$-modul fraksional kiri di $Q(W)$ yaitu terdapat elemen reguler $c \in C_{R}(0)$ sedemikian hingga $W^{\prime} c \subseteq W$. Selanjutnya akan dibuktikan $\left(S: W^{\prime}\right)_{r}$ merupakan $S$-modul fraksional kanan di $Q(V)$. Dengan memanfaatkan $W^{\prime} c \subseteq W$, dapat dibuktikan bahwa $\left(S: W^{\prime}\right)_{r} Q(S)=Q(V)$. Lebih lanjut, dengan menggunakan $V W^{\prime}$ sebagai $R$-ideal di $Q(R)$, terdapat elemen reguler $t \in V W^{\prime}$ sedemikian sehingga $t\left(S: W^{\prime}\right)_{r} \subseteq V W^{\prime}\left(S: W^{\prime}\right)_{r} \subseteq V$. Terbukti, $\left(S: W^{\prime}\right)_{r}$ merupakan $S$-modul fraksional kanan di $Q(V)$.

Lemma 2.14 4] Diberikan order $T=\left(\begin{array}{cc}R & V \\ W & S\end{array}\right)$ di ring $Q(T)=\left(\begin{array}{cc}Q(R) & Q(V) \\ Q(W) & Q(S)\end{array}\right)$. Jika $R$ merupakan order maksimal di $Q(R)$ dan $S$ merupakan order maksimal di $Q(S)$ maka:

(1) $\left(S: V^{\prime}\right)_{l}=\left(V^{\prime}\right)^{-1}=\left(R: V^{\prime}\right)_{r}$ untuk setiap $(R, S)$-modul fraksional $V^{\prime}$ di $Q(V)$ dengan $\left(V^{\prime}\right)^{-1}=\left\{\bar{w} \in Q(W) \mid V^{\prime} \bar{w} V^{\prime} \subseteq V^{\prime}\right\} ;$

(2) $\left(S: W^{\prime}\right)_{r}=\left(W^{\prime}\right)^{-1}=\left(R: W^{\prime}\right)_{l}$ untuk setiap $(S, R)$-modul fraksional $W^{\prime}$ di $Q(W)$ dengan $\left(W^{\prime}\right)^{-1}=\left\{\bar{v} \in Q(V) \mid W^{\prime} \bar{v} W^{\prime} \subseteq W^{\prime}\right\}$.

Bukti. Diketahui $R$ merupakan order maksimal di $Q(R)$ dan $S$ merupakan order maksimal di $Q(S)$.

(1) Diambil sebarang $(R, S)$-modul fraksional $V^{\prime}$ di $Q(V)$ yang berarti $c \in$ $C_{R}(0), d \in C_{S}(0)$ sedemikian sehingga $c V^{\prime} \subseteq V$ dan $V^{\prime} d \subseteq V$. Akan dibuktikan terlebih dahulu $\left(S: V^{\prime}\right)_{l}=\left(V^{\prime}\right)^{-1}$. Apabila diperhatikan $V^{\prime}\left(S: V^{\prime}\right)_{l} V^{\prime} \subseteq V^{\prime}$. Jadi, $\left(S: V^{\prime}\right)_{l} \subseteq\left(V^{\prime}\right)^{-1}$. Sebaliknya, diambil sebarang $\bar{w} \in\left(V^{\prime}\right)^{-1}$ yang berarti $V^{\prime} \bar{w} V^{\prime} \subseteq V^{\prime}$. Akibatnya, $W c V^{\prime} \bar{w} V^{\prime} \subseteq W c V^{\prime}$ dan $W c V^{\prime} \subseteq W V \subseteq S$. Apabila diperhatikan, $W c V^{\prime} \neq 0$ karena $c \in C_{R}(0)$. Sehingga didapatkan $W c V^{\prime}$ merupakan ideal tak nol di $S$ (Lemma 1.1, [5] ). Karena $S$ merupakan order maksimal, haruslah $O_{r}\left(W c V^{\prime}\right)=S$. Diketahui bahwa $\bar{w} V^{\prime} \subseteq O_{r}\left(W c V^{\prime}\right)=S$. Sehingga diperoleh $\bar{w} \in\left(S: V^{\prime}\right)_{l}$. Terbukti, $\left(S: V^{\prime}\right)_{l}=\left(V^{\prime}\right)^{-1}$.

Selanjutnya akan dibuktikan $\left(R: V^{\prime}\right)_{r}=\left(V^{\prime}\right)^{-1}$. Karena $V^{\prime}\left(R: V^{\prime}\right)_{r} V^{\prime} \subseteq$ $V^{\prime}$, diperoleh $\left(R: V^{\prime}\right)_{r} \subseteq\left(V^{\prime}\right)^{-1}$. Diambil sebarang $\bar{w} \in\left(V^{\prime}\right)^{-1}$ yang berarti $V^{\prime} \bar{w} V^{\prime} \subseteq V^{\prime}$. Dengan memanfaatkan $V^{\prime} d \subseteq V$ dan $V^{\prime} d W$ sebagai ideal tak nol, dapat ditunjukkan bahwa $\bar{w} \in\left(R: V^{\prime}\right)_{r}$. Sehingga didapatkan $\left(R: V^{\prime}\right)_{r}=\left(V^{\prime}\right)^{-1}$. Terbukti, $\left(S: V^{\prime}\right)_{l}=\left(V^{\prime}\right)^{-1}=\left(R: V^{\prime}\right)_{r}$.

(2) Diambil sebarang $W^{\prime}$ yang merupakan $(S, R)$-modul fraksional di $Q(W)$ yaitu terdapat $c^{\prime} \in C_{R}(0), d^{\prime} \in C_{S}(0)$ sedemikian sehingga $W^{\prime} c^{\prime} \subseteq W$ dan $d^{\prime} W^{\prime} \subseteq W$. Akan dibuktikan terlebih dahulu $\left(S: W^{\prime}\right)_{r}=\left(W^{\prime}\right)^{-1}$. Apabila diperhatikan $W^{\prime}\left(S: W^{\prime}\right)_{r} W^{\prime} \subseteq W^{\prime}$. Jadi, $\left(S: W^{\prime}\right)_{r} \subseteq\left(V^{\prime}\right)^{-1}$. 
Sebaliknya, diambil sebarang $\bar{v} \in W^{\prime-1}$ yang berarti $W^{\prime} \bar{v} W^{\prime} \subseteq W^{\prime}$. Akibatnya, $V d^{\prime} W^{\prime} \bar{v} W^{\prime} \subseteq V d^{\prime} W^{\prime}$ dan $V d^{\prime} W^{\prime} \subseteq V W \subseteq R$. Apabila diperhatikan $V d^{\prime} W^{\prime} \neq 0$, karena $d^{\prime} \in C_{S}(0)$, sehingga diperoleh $V d^{\prime} W^{\prime}$ ideal tak nol di $R$. Oleh karena itu, $V d^{\prime} W^{\prime}$ merupakan $R$-ideal. Mengingat $R$ merupakan order maksimal, haruslah $O_{r}\left(V d^{\prime} W^{\prime}\right)=R$. Diketahui bahwa $\bar{v} W^{\prime} \subseteq O_{r}\left(V d^{\prime} W^{\prime}\right)=R$ yang berarti $\bar{v} \in\left(R: W^{\prime}\right)_{l}$. Terbukti, $\left(R: W^{\prime}\right)_{l}=$ $W^{\prime-1}$.

Selanjutnya akan dibuktikan $\left(S: W^{\prime}\right)_{r}=\left(W^{\prime}\right)^{-1}$. Karena $W^{\prime}\left(S: W^{\prime}\right)_{r} W^{\prime}$ $\subseteq W^{\prime}$, didapatkan $\left(S: W^{\prime}\right)_{r} \subseteq W^{\prime-1}$. Diambil sebarang $\bar{v} \in W^{\prime-1}$ yang berarti $W^{\prime} \bar{v} W^{\prime} \subseteq W^{\prime}$. Dengan memanfaatkan $W c^{\prime} \subseteq W$ dan $W^{\prime} c V$ sebagai ideal tak nol di $S$, dapat ditunjukkan bahwa $\bar{v} \in\left(S: W^{\prime}\right)_{r}$. Sehingga diperoleh $\left(S: W^{\prime}\right)_{r}=\left(W^{\prime}\right)^{-1}$. Terbukti, $\left(S: W^{\prime}\right)_{r}=W^{\prime-1}=\left(R: W^{\prime}\right)_{l}$.

Diberikan order $R$ dalam ring $Q(R)$ dan suatu $R$-ideal $I$ di $Q(R) . I$ disebut v- ideal jika ${ }_{v} I=I=I_{v}$ dengan $\left(R:(R: I)_{r}\right)_{l}={ }_{v} I$ dan $\left(R:(R: I)_{l}\right)_{r}=I_{v}$. Hal ini kemudian memotivasi definisi suatu $v-(R, S)$-modul di $Q(V)$ dan suatu $v-(S, R)$-modul di $Q(W)$ sebagai berikut $[4]$.

Definisi 2.15 Diberikan ring konteks Morita $T$ di ring $Q(T)$. Diberikan suatu $(R, S)$-modul fraksional $V^{\prime}$ di $Q(V)$ dan suatu $(S, R)$-modul fraksional $W^{\prime} d i$ $Q(W)$.

(1) $\operatorname{Suatu}(R, S)$-modul fraksional $V^{\prime}$ di $Q(V)$ disebut $v-(R, S)$-modul jika $V_{v}^{\prime}=V^{\prime}={ }_{v} V^{\prime}$ dengan $\left(S:\left(S: V^{\prime}\right)_{l}\right)_{r}=V_{v}^{\prime}$ dan $\left(R:\left(R: V^{\prime}\right)_{r}\right)_{l}={ }_{v} V^{\prime}$.

(2) $\operatorname{Suatu}(S, R)$-modul fraksional $W^{\prime}$ di $Q(W)$ disebut $v-(S, R)$ - modul jika $W_{v}^{\prime}=W^{\prime}={ }_{v} W^{\prime}$ dengan $\left(S:\left(S: W^{\prime}\right)_{r}\right)_{l}={ }_{v} W^{\prime}$ dan $\left(R:\left(R: W^{\prime}\right)_{l}\right)_{r}=$ $W_{v}^{\prime}$

Berikut akan diberikan contoh suatu $(R, S)$-modul fraksional yang merupakan $v-(R, S)$-modul di $Q(V)$ dan yang bukan merupakan $v-(R, S)$-modul di $Q(V)$.

Contoh 2.16 Diberikan ring konteks Morita $T=\left(\begin{array}{ll}\mathbb{Z}[x] & \mathbb{Z}[x] \\ \mathbb{Z}[x] & \mathbb{Z}[x]\end{array}\right)$ di $\operatorname{ring} Q(T)=$ $\left(\begin{array}{ll}\mathbb{Q}[x] & \mathbb{Q}[x] \\ \mathbb{Q}[x] & \mathbb{Q}[x]\end{array}\right)$. Misalkan $V^{\prime}=\langle 2, x\rangle$ yang merupakan $(\mathbb{Z}[x], \mathbb{Z}[x])$-modul fraksional di $\mathbb{Q}[x]$. Jadi, didapatkan $\left(\mathbb{Z}[x]:\left(\mathbb{Z}[x]: V^{\prime}\right)_{l}\right)_{r}=(\mathbb{Z}[x]: \mathbb{Z}[x])_{l}=\mathbb{Z}[x]$. Jadi, $V^{\prime}$ bukan merupakan $v-(\mathbb{Z}[x], \mathbb{Z}[x])$-modul di $\mathbb{Q}[x]$. Selanjutnya, apabila diperhatikan untuk $V=\mathbb{Z}[x]$, berlaku $(\mathbb{Z}[x]: \mathbb{Z}[x])_{l}=\mathbb{Z}[x]$. Oleh karena itu, diperoleh $V_{v}=\left(\mathbb{Z}[x]:(\mathbb{Z}[x]: \mathbb{Z}[x])_{l}\right)_{r}=(\mathbb{Z}[x]: \mathbb{Z}[x])_{r}=\mathbb{Z}[x]$. Jadi, dapat disimpulkan bahwa $V$ merupakan $v-(R, S)$-modul di $Q(V)$. 
Lemma 2.17 [4] Diberikan order $T=\left(\begin{array}{cc}R & V \\ W & S\end{array}\right)$ di ring $Q(T)=\left(\begin{array}{cc}Q(R) & Q(V) \\ Q(W) & Q(S)\end{array}\right)$. Jika $V^{\prime}$ merupakan $(R, S)$-modul fraksional di $Q(V), W^{\prime}$ merupakan $(S, R)$ - modul fraksional di $Q(W)$, I merupakan $R$-ideal di $Q(R)$ dan $J$ merupakan $S$-ideal di $Q(S)$ maka

(1) ${ }_{v}\left(I V^{\prime}\right)={ }_{v}\left({ }_{v} I V^{\prime}\right)$ dan $\left(V^{\prime} J\right)_{v}=\left(V^{\prime} J_{v}\right)_{v}$,

(2) ${ }_{v}\left(J W^{\prime}\right)={ }_{v}\left({ }_{v} J W^{\prime}\right)$ dan $\left(W^{\prime} I\right)_{v}=\left(W^{\prime} I_{v}\right)_{v}$.

Bukti. Diketahui $V^{\prime}$ merupakan $(R, S)$-modul fraksional di $Q(V)$, $W^{\prime}$ merupakan $(S, R)$-modul fraksional di $Q(W), I$ merupakan $R$-ideal di $Q(R)$ dan $J$ merupakan $S$-ideal di $Q(S)$.

(1) Pertama-tama akan ditunjukkan bahwa ${ }_{v}\left(I V^{\prime}\right)={ }_{v}\left({ }_{v} I V^{\prime}\right)$ yaitu $(R$ : $\left.\left(R: I V^{\prime}\right)_{r}\right)_{l}=\left(R:\left(R:{ }_{v} I V^{\prime}\right)_{r}\right)_{l}$. Dalam hal ini akan ditunjukkan $\left(R: I V^{\prime}\right)_{r}=\left(R:{ }_{v} I V^{\prime}\right)_{r}$. Diketahui bahwa $I V^{\prime} \subseteq{ }_{v} I V^{\prime}$ sehingga berlaku $\left(R:{ }_{v} I V^{\prime}\right)_{r} \subseteq\left(R: I V^{\prime}\right)_{r}$. Selanjutnya, diambil sebarang $\bar{w} \in\left(R: I V^{\prime}\right)_{r}$ maka berarti $I V^{\prime} \bar{w} \subseteq R$. Jadi, diperoleh $V^{\prime} \bar{w} \subseteq(R: I)_{r}$ dan ${ }_{v} I V^{\prime} \bar{w} \subseteq$ ${ }_{v} I(R: I)_{r}=\left(R:(R: I)_{r}\right)_{l}(R: I)_{r} \subseteq R$. Dengan demikian diperoleh $\bar{w} \in\left(R:{ }_{v} I V^{\prime}\right)_{l}$. Dengan kata lain, $\left.\left(R: I V^{\prime}\right)_{r}=\left(R:{ }_{v} I V^{\prime}\right)_{r}\right)_{l}$ sehingga didapatkan ${ }_{v}\left(I V^{\prime}\right)={ }_{v}\left({ }_{v} I V^{\prime}\right)$.

Selanjtunya akan dibuktikan $\left(V^{\prime} J\right)_{v}=\left(V^{\prime} J_{v}\right)_{v}$ yaitu $\left(S:\left(S: V^{\prime} J\right)_{l}\right)_{r}=$ $\left(S:\left(S: V^{\prime} J_{v}\right)_{l}\right)_{r}$. Dengan cara analog pada pembuktian di atas, dapat dibuktikan $\left(S: V^{\prime} J\right)_{l}=\left(S: V^{\prime} J_{v}\right)_{l}$. Terbukti, $\left(V^{\prime} J\right)_{v}=\left(V^{\prime} J_{v}\right)_{v}$.

(2) Pada bagian ini akan dibuktikan ${ }_{v}\left(J W^{\prime}\right)={ }_{v}\left({ }_{v} J W^{\prime}\right)$ yaitu $(S:(S:$ $\left.\left.J W^{\prime}\right)_{r}\right)_{l}=\left(S:\left(S:{ }_{v} J W\right)_{r}\right)_{l}$. Dalam hal ini akan ditunjukkan $(S$ : $\left.{ }_{v} J W\right)_{r}=(S: J W)_{r}$. Diketahui bahwa $J W \subseteq{ }_{v} J W$ sehingga berlaku $\left(S:{ }_{v} J W^{\prime}\right)_{r} \subseteq\left(S: J W^{\prime}\right)_{r}$. Selanjutnya, diambil sebarang $\bar{v} \in(S:$ $\left.J W^{\prime}\right)_{r}$ yang berarti $J W^{\prime} \bar{v} \subseteq S$. Jadi, diperoleh $W^{\prime} \bar{v} \subseteq(S: J)_{r}$ dan ${ }_{v} J W^{\prime} \bar{v} \subseteq{ }_{v} J(S: J)_{r}=\left(S:(S: J)_{r}\right)_{l}(S: J)_{r} \subseteq S$. Dengan demikian, $\bar{v} \in\left(S:{ }_{v} J W^{\prime}\right)_{l}$. Dengan kata lain, $\left(S:{ }_{v} J W\right)_{r}=(S: J W)_{r}$ sehingga didapatkan ${ }_{v}\left(J W^{\prime}\right)={ }_{v}\left({ }_{v} J W^{\prime}\right)$.

Selanjutnya akan dibuktikan $\left(W^{\prime} I\right)_{v}=\left(W^{\prime} I_{v}\right)_{v}$ yaitu $\left(R:\left(R: W^{\prime} I\right)_{l}\right)_{r}=$ $\left(R:\left(R: W^{\prime} I_{v}\right)_{l}\right)_{r}$. Dengan cara analog pada pembuktian di atas, dapat dibuktikan $\left.\left(R: W^{\prime} I\right)_{l}=\left(R: W^{\prime} I_{v}\right)_{l}\right)_{r}$. Terbukti, $\left(W^{\prime} I\right)_{v}=\left(W^{\prime} I_{v}\right)_{v}$.

Lemma 2.18 [4] Diberikan order $T=\left(\begin{array}{cc}R & V \\ W & S\end{array}\right)$ diring $Q(T)=\left(\begin{array}{cc}Q(R) & Q(V) \\ Q(W) & Q(S)\end{array}\right)$. Jika $R$ merupakan order maksimal $R$ di ring $Q(R)$ dan $S$ merupakan order maksimal di $Q(S)$ maka

(1) $\left(W^{\prime} V^{\prime}\right)_{v}=\left(W_{v}^{\prime} V^{\prime}\right)_{v}=\left(W^{\prime} V_{v}^{\prime}\right)_{v}$,

(2) $\left(V^{\prime} W^{\prime}\right)_{v}=\left(V_{v}^{\prime} W^{\prime}\right)_{v}=\left(V^{\prime} W_{v}^{\prime}\right)_{v}$. 
untuk setiap $(R, S)$-modul fraksional $V^{\prime}$ di $Q(V)$ dan $(S, R)$-modul fraksional $W^{\prime}$ di $Q(W)$.

Bukti. Diketahui $R$ merupakan order maksimal $R$ di $\operatorname{ring} Q(R)$ dan $S$ merupakan order maksimal di $Q(S)$.

(1) Akan ditunjukkan terlebih dahulu $\left(W^{\prime} V^{\prime}\right)_{v}=\left(W_{v}^{\prime} V^{\prime}\right)_{v}$ yaitu $(S:(S$ : $\left.\left.W^{\prime} V^{\prime}\right)_{l}\right)_{r}=\left(S:\left(S: W_{v}^{\prime} V^{\prime}\right)_{l}\right)_{r}$. Dalam hal ini akan ditunjukkan $(S$ : $\left.W^{\prime} V^{\prime}\right)_{l}=\left(S: W_{v}^{\prime} V^{\prime}\right)_{l}$. Apabila diperhatikan bahwa $W^{\prime} V^{\prime} \subseteq W_{v}^{\prime} V^{\prime}$, yang berarti $\left(S: W_{v}^{\prime} V^{\prime}\right)_{l} \subseteq\left(S: W^{\prime} V^{\prime}\right)_{l}$. Sebaliknya diambil sebarang $q \in$ $\left(S: W^{\prime} V^{\prime}\right)_{l}$ dengan $q$ merupakan elemen reguler di $Q(R)$ yang berarti $q W^{\prime} V^{\prime} \subseteq S$. Karena $S$ merupakan order maksimal, berdasarkan Lemma 2.14 berlaku $q W^{\prime} \subseteq\left(S: V^{\prime}\right)_{l}=\left(V^{\prime}\right)^{-1}$.

Pertama-tama akan dibuktikan terlebih dahulu $\left(R: W^{\prime}\right)_{l} q^{-1}=(R$ : $\left.q W^{\prime}\right)_{l}$. Diambil sebarang $\bar{v} \in\left(R: q W^{\prime}\right)_{l}$ yang berarti $\bar{v} q W^{\prime} \subseteq R$. Jadi, $\bar{v} q \in\left(R: W^{\prime}\right)_{l}$ dan $\bar{v} \in\left(R: W^{\prime}\right)_{l} q^{-1}$. Sebaliknya, untuk setiap $\bar{v} q^{-1} \in$ $\left(R: W^{\prime}\right)_{l} q^{-1}$ untuk suatu $\bar{v} \in\left(R: W^{\prime}\right)_{l}$. Oleh karena itu, $\bar{v} q^{-1} q W^{\prime} \subseteq R$ dan $\bar{v} q^{-1} \in\left(R: q W^{\prime}\right)_{l}$. Terbukti, $\left(R: W^{\prime}\right)_{l} q^{-1}=\left(R: q W^{\prime}\right)_{l}$.

Selanjutnya akan ditunjukkan $q W_{v}^{\prime}=\left(q W^{\prime}\right)_{v}$ yaitu $q\left(R:\left(R: W^{\prime}\right)_{l}\right)_{r}=$ $\left(R:\left(R: q W^{\prime}\right)_{l}\right)_{r}$. Diambil sebarang $q \bar{w} \in q\left(R:\left(R: W^{\prime}\right)_{l}\right)_{r}$ untuk suatu $\bar{w} \in\left(R:\left(R: W^{\prime}\right)_{l}\right)_{r}$ yang berarti $\left(R: W^{\prime}\right)_{l} \bar{w} \subseteq R$ sehingga $\left(R: q W^{\prime}\right)_{l} q \bar{w}=(R: W)_{l} q^{-1} q \bar{w} \subseteq R$. Jadi, didapatkan $q \bar{w} \in(R:$ $\left.\left(R: q W^{\prime}\right)_{l}\right)_{r}=\left(q W^{\prime}\right)_{v}$. Sebaliknya, untuk setiap $\bar{w} \in\left(q W^{\prime}\right)_{v}$ yaitu $\left(R: q W^{\prime}\right)_{l} \bar{w} \subseteq R$. Jadi, $\left(R: W^{\prime}\right)_{l} q^{-1} \bar{w}=\left(R: q W^{\prime}\right)_{l} \bar{w} \subseteq R$ dan $q^{-1} \bar{w} \in W_{v}^{\prime}$. Oleh karena itu, haruslah $\bar{w} \in q W_{v}^{\prime}$.

Apabila diperhatikan $\left(V^{\prime}\right)^{-1} \subseteq\left(V^{\prime-1}\right)_{v}=\left(R:\left(R: V^{\prime-1}\right)_{l}\right)_{r}=(R$ : $\left.{ }_{v} V^{\prime}\right)_{r} \subseteq\left(R: V^{\prime}\right)_{r}=V^{\prime-1}$. Jadi, $\left(\left(V^{\prime}\right)^{-1}\right)_{v}=V^{\prime-1}$. Sehingga didapatkan $q W_{v}^{\prime}=\left(q W^{\prime}\right)_{v} \subseteq\left(\left(V^{\prime}\right)^{-1}\right)_{v}=\left(V^{\prime}\right)^{-1}$. Jadi, diperoleh $q W_{v}^{\prime} V^{\prime} \subseteq$ $\left(V^{\prime}\right)^{-1} V^{\prime} \subseteq S$ dan $q \in\left(S: W_{v}^{\prime} V^{\prime}\right)$. Akibatnya, $\left(W^{\prime} V^{\prime}\right)_{v}=\left(W_{v}^{\prime} V^{\prime}\right)_{v}$ (Teorema $1.21,[1]$ ).

Lebih lanjut untuk membuktikan $\left(W^{\prime} V^{\prime}\right)_{v}=\left(W^{\prime} V_{v}^{\prime}\right)_{v}$ yaitu $(S:(S$ : $\left.\left.W^{\prime} V^{\prime}\right)_{l}\right)_{r}=\left(S:\left(S: W^{\prime} V_{v}^{\prime}\right)_{l}\right)_{r}$ dapat ditunjukkan dengan analog pada pembuktian di atas yaitu dengan membuktikan $\left(S: W^{\prime} V^{\prime}\right)_{l}=\left(S: W^{\prime} V_{v}^{\prime}\right)_{l}$. Terbukti, $\left(W^{\prime} V^{\prime}\right)_{v}=\left(W_{v}^{\prime} V^{\prime}\right)_{v}=\left(W^{\prime} V_{v}^{\prime}\right)_{v}$.

(2) Akan dibuktikan $\left(V^{\prime} W^{\prime}\right)_{v}=\left(V_{v}^{\prime} W^{\prime}\right)_{v}=\left(V^{\prime} W_{v}^{\prime}\right)_{v}$ yaitu $\left(R:\left(R: V^{\prime} W^{\prime}\right)_{l}\right)_{r}$ $=\left(R:\left(R: V_{v}^{\prime} W^{\prime}\right)_{l}\right)_{r}=\left(R:\left(R: V^{\prime} W_{v}^{\prime}\right)_{l}\right)_{r}$. Dengan cara analog pada poin (1), dapat ditunjukkan $\left(R: V^{\prime} W^{\prime}\right)_{l}=\left(R: V_{v}^{\prime} W^{\prime}\right)_{l}$ dan $\left(R: V^{\prime} W^{\prime}\right)_{l}=$ $\left(\left(R: V^{\prime} W_{v}^{\prime}\right)_{l}\right.$. 


\section{RING KONTEKS MORITA SEBAGAI ORDER MAKSIMAL}

Diberikan ring konteks Morita $T=\left(\begin{array}{cc}R & V \\ W & S\end{array}\right)$ di ring Artin sederhana $Q(T)=$ $\left(\begin{array}{cc}Q(R) & Q(V) \\ Q(W) & Q(S)\end{array}\right)$. Pada bagian ini akan diberikan syarat perlu dan cukup sehingga ring konteks Morita merupakan order yang lebih khusus yaitu order maksimal.

Proposisi 3.1 4] Diberikan order $T=\left(\begin{array}{cc}R & V \\ W & S\end{array}\right)$ di ring $Q(T)=\left(\begin{array}{cc}Q(R) & Q(V) \\ Q(W) & Q(S)\end{array}\right)$. Pernyataan-pernyataan berikut ekuivalen.

(1) (a) $O_{l}\left(V^{\prime}\right)=R$ dan $O_{r}\left(V^{\prime}\right)=S$ untuk setiap $(R, S)$-modul integral $V^{\prime}$ di $Q(V)$.

(b) $O_{l}\left(W^{\prime}\right)=S$ dan $O_{r}\left(W^{\prime}\right)=R$ untuk setiap $(S, R)$ - modul integral $W^{\prime}$ di $Q(W)$.

(2) $V$ merupakan $(R, S)$ - modul maksimal di $Q(V)$ dan $W$ merupakan $(R, S)$ modul maksimal di $Q(W)$.

(3) (a) $\left(\left(V^{\prime}\right)^{-1} V^{\prime}\right)_{v}=S$ dan ${ }_{v}\left(V^{\prime}\left(V^{\prime}\right)^{-1}\right)=R$ untuk setiap $(R, S)$ - modul fraksional $V^{\prime}$ di $Q(V$.

(b) $\left(\left(W^{\prime}\right)^{-1} W^{\prime}\right)_{v}=R$ dan $_{v}\left(W^{\prime}\left(W^{\prime}\right)^{-1}\right)=S$ untuk setiap $(S, R)-$ modul fraksional $W^{\prime}$ di $Q(W)$.

Bukti. (1) $\Rightarrow(2)$ Diambil sebarang $q \in O_{r}\left(V^{\prime}\right)$ yang berarti $V^{\prime} q \subseteq V^{\prime}$. Karena $V^{\prime}$ merupakan $(R, S)$-modul fraksional, berarti terdapat $c \in C_{R}(0)$ sedemikan sehingga $c V^{\prime} \subseteq V$. Jadi, didapatkan $R c V^{\prime} q \subseteq R c V^{\prime} \subseteq V$. Akibatnya, diperoleh pula bahwa $q \in O_{r}\left(R c V^{\prime}\right)=S$. dan $O_{r}\left(V^{\prime}\right)=S$. Dengan cara yang sama dapat ditunjukkan $O_{l}\left(V^{\prime}\right)=R$. Dengan cara yang sama dapat pula ditunjukkan bahwa $W$ merupakan $(R, S)$-modul maksimal di $Q(W)$.

$(2) \Rightarrow(3)$ Diambil sebarang $(R, S)-$ modul fraksional $V^{\prime}$ di $Q(V)$. Berdasarkan Lemma 2.11 dan Lemma 2.14 berlaku $\left(V^{\prime}\right)^{-1}=\left(S: V^{\prime}\right)_{l}=\left(R: V^{\prime}\right)_{r}$. Selanjutnya akan ditunjukkan bahwa $\left(\left(V^{\prime}\right)^{-1} V^{\prime}\right)_{v}=\left(S:\left(S:\left(V^{\prime}\right)^{-1} V^{\prime}\right)_{l}\right)_{r}=S$. Dalam hal ini akan dibuktikan $\left(S:\left(V^{\prime}\right)^{-1} V^{\prime}\right)_{l}=S$. Diambil sebarang $q \in\left(S:\left(V^{\prime}\right)^{-1} V^{\prime}\right)_{l}$. Akibatnya, didapatkan $q\left(V^{\prime}\right)^{-1} \subseteq\left(V^{\prime}\right)^{-1}$ dan $q \in O_{l}\left(\left(V^{\prime}\right)^{-1}\right)=S$, sehingga berlaku $\left(S:\left(V^{\prime}\right)^{-1} V^{\prime}\right)_{l} \subseteq S$. Dengan demikian diperoleh $\left(S:\left(V^{\prime}\right)^{-1} V^{\prime}\right)_{l}=S$ dan $\left(\left(V^{\prime}\right)^{-1} V^{\prime}\right)_{v}=\left(S:\left(S:\left(V^{\prime}\right)^{-1} V^{\prime}\right)_{l}\right)_{r}=S$. Dengan cara yang sama dapat ditunjukkan pula ${ }_{v}\left(V^{\prime}\left(V^{\prime}\right)^{-1}\right)=R$.

$(3) \Rightarrow(1)$ Diambil sebarang $(R, S)$-modul fraksinal integral $V^{\prime}$ di $Q(V)$. Akan dibuktikan $O_{l}\left(V^{\prime}\right)=R$ dan $O_{r}\left(V^{\prime}\right)=S$. Jelas bahwa $R \subseteq O_{l}\left(V^{\prime}\right)=R$ dan $S \subseteq O_{r}\left(V^{\prime}\right)$. Diambil sebarang $q \in O_{l}\left(V^{\prime}\right)$ dengan $q$ merupakan elemen reguler di $Q(R)$ yang berarti $q V^{\prime} \subseteq V^{\prime}$ dan $\left(V^{\prime}\right)^{-1} q V^{\prime} \subseteq\left(V^{\prime}\right)^{-1} V^{\prime} \subseteq\left(\left(V^{\prime}\right)^{-1} V^{\prime}\right)_{v}=S$. Jadi, $\left(V^{\prime}\right)^{-1} q \subseteq\left(S: V^{\prime}\right)_{l} \subseteq\left(V^{\prime}\right)^{-1}$ sehingga $q \in R q={ }_{v}\left(V^{\prime}\left(V^{\prime}\right)^{-1}\right) q={ }_{v}\left(V^{\prime}\left(V^{\prime}\right)^{-1} q\right) \subseteq$ 
${ }_{v}\left(V^{\prime}\left(V^{\prime}\right)^{-1}\right)=R$. Dari sini, berlaku $q \in R$. Jadi, $O_{l}\left(V^{\prime}\right)=R$. Dengan cara yang sama dapat pula ditunjukkan bahwa $O_{r}\left(V^{\prime}\right)=S$. Terbukti, $V$ merupakan $(R, S)$-modul maksimal di $Q(V)$.

Berikut akan diberikan contoh ring konteks Morita $T=\left(\begin{array}{cc}R & V \\ W & S\end{array}\right)$ yang bukan merupakan order maksimal di ring $Q(T)=\left(\begin{array}{cc}Q(R) & Q(V) \\ Q(W) & Q(S)\end{array}\right)$ meskipun ring $R$ dan $S$ merupakan order maksimal.

Contoh 3.2 Diberikan ring konteks Morita $T=\left(\begin{array}{cc}\mathbb{Z} & 2 \mathbb{Z} \\ \mathbb{Z} & \mathbb{Z}\end{array}\right)$ di $\operatorname{ring} Q(T)=\left(\begin{array}{ll}\mathbb{Q} & \mathbb{Q} \\ \mathbb{Q} & \mathbb{Q}\end{array}\right)$. Apabila diperhatikan $A=\left(\begin{array}{ll}2 \mathbb{Z} & 22 \mathbb{Z} \\ 2 \mathbb{Z} & 22 \mathbb{Z}\end{array}\right)$ merupakan $T$-ideal integral di $Q(T)$. Jadi, berlaku $O_{l}(A)=\left(\begin{array}{cc}\mathbb{Z} & 2 \mathbb{Z} \\ \frac{1}{2} \mathbb{Z} & \mathbb{Z}\end{array}\right)$ dan $O_{r}(A)=\left(\begin{array}{cc}\mathbb{Z} & \mathbb{Z} \\ 2 \mathbb{Z} & \mathbb{Z}\end{array}\right)$. Jadi, terdapat $T$-ideal integral yaitu $A$ dengan $O_{l}(A) \neq T$ dan $O_{r}(A) \neq T$. Oleh karena itu, diperoleh $T$ bukan merupakan order maksimal di ring $Q(T)$.

Berikut akan diberikan syarat perlu dan cukup bilamana ring konteks Morita $T$ merupakan order maksimal di ring $Q(T)$.

Teorema 3.3 [4] Diberikan order $T=\left(\begin{array}{cc}R & V \\ W & S\end{array}\right)$ dalam ring $Q(T)=\left(\begin{array}{cc}Q(R) & Q(V) \\ Q(W) & Q(S)\end{array}\right)$. Pernyataan-pernyataan berikut ekuivalen.

(1) $T$ merupakan order maksimal.

(2) (a) Ring $R$ merupakan order maksimal di $Q(R)$ dan ring $S$ merupakan order maksimal di $Q(S)$.

(b) $(R: W)_{l}=V=(S: W)_{r}$ dan $(R: V)_{l}=W=(S: V)_{r}$.

(3) (a) $V$ merupakan $(R, S)$-modul maksimal di $Q(V)$ dan $W$ merupakan $(S, R)$ - modul maksimal di $Q(W)$.

(b) $(R: W)_{l}=V=(S: W)_{r}$ dan $(R: V)_{l}=W=(S: V)_{r}$.

(4) (a) $V$ modul maksimal di $Q(V)$ dan $W$ modul maksimal di $Q(W)$.

(b) $(V W)_{v}=R={ }_{v}(V W)$ dan $(W V)_{v}=S={ }_{v}(W V)$.

(c) $V_{v}=V={ }_{v} V$ dan $W_{v}=W={ }_{v} W$.

Bukti. (1) $\Rightarrow(2)$ Diambil sebarang $R$-ideal integral $I$ di $Q(R)$. Untuk setiap $\bar{r} \in O_{r}(I)$, dibentuk himpunan matriks $A=\left(\begin{array}{cc}I & I V \\ W I & W I V\end{array}\right)$. Menurut Lemma 2.8 diperoleh $A$ merupakan $T$-ideal integral. Misalkan $\bar{t}=\left(\begin{array}{ll}\bar{r} & 0 \\ 0 & 0\end{array}\right)$. Jadi, didapatkan 
$\left(\begin{array}{cc}I & I V \\ W I & W I V\end{array}\right) \bar{t}=\left(\begin{array}{cc}I & I V \\ W I & W I V\end{array}\right)\left(\begin{array}{cc}\bar{r} & 0 \\ 0 & 0\end{array}\right) \subseteq\left(\begin{array}{cc}I \bar{r} & 0 \\ W I \bar{r} & 0\end{array}\right) \subseteq\left(\begin{array}{cc}I & I V \\ W I & W I V\end{array}\right)$. Jadi $\bar{t} \in O_{r}(A)=T$ dan $\bar{r} \in R$. Dengan demikian diperoleh $O_{r}(I)=R$. Dengan cara yang sama dapat pula ditunjukkan $O_{l}(I)=R$. Terbukti, $R$ order maksimal. Dengan analog dapat ditunjukkan $S$ order maksimal.

Selanjutnya akan ditunjukkan $V=(R: W)_{l}$. Jelas bahwa $V \subseteq(R: W)_{l}$. Sebaliknya, diambil sebarang $\bar{v} \in(R: W)_{l}$. Dibentuk $A=\left(\begin{array}{cc}R & V \\ W & W V\end{array}\right)$. Menurut Lemma 2.8 berlaku $A$ merupakan $T$-ideal. Misalkan $\bar{t}=\left(\begin{array}{cc}0 & 0 \\ \bar{v} & 0\end{array}\right)$, berlaku

$$
\bar{t}\left(\begin{array}{cc}
R & V \\
W & W V
\end{array}\right)=\left(\begin{array}{cc}
0 & \bar{v} \\
0 & 0
\end{array}\right)\left(\begin{array}{cc}
R & V \\
W & W V
\end{array}\right) \subseteq\left(\begin{array}{cc}
\bar{v} W & \bar{v} W V \\
0 & 0
\end{array}\right) \subseteq\left(\begin{array}{cc}
R & V \\
W & S
\end{array}\right)
$$

sehingga $\bar{t} \in O_{l}(A)=T$. Akibatnya $\bar{v} \in V$. Dengan demikian diperoleh $V=(R$ : $W)_{l}$. Analog untuk menunjukkan $V=(S: W)_{r}$. Dengan cara yang sama dapat ditunjukkan $(R: V)_{l}=R=(S: V)_{r}$.

(2) $\Rightarrow(1)$ Misalkan $A=\left(\begin{array}{cc}I & V^{\prime} \\ W^{\prime} & J\end{array}\right)$ merupakan $T$-ideal integral. Diambil sebarang $\bar{t}=\left(\begin{array}{cc}\bar{r} & \bar{v} \\ \bar{w} & \bar{s}\end{array}\right) \in O_{r}(T)$ yang berarti $\left(\begin{array}{cc}I & V^{\prime} \\ W^{\prime} & J\end{array}\right)\left(\begin{array}{cc}\bar{r} & \bar{v} \\ \bar{w} & \bar{s}\end{array}\right) \subseteq\left(\begin{array}{cc}I & V^{\prime} \\ W^{\prime} & J\end{array}\right)$. Akibatnya $I \bar{r} \subseteq I, J \bar{s} \subseteq J, I \bar{v} \subseteq V^{\prime}$, dan $J \bar{w} \subseteq W^{\prime}$ sehingga $\bar{r} \in O_{r}(I)$ dan $\bar{s} \in O_{r}(J)$. Karena $R$ dan $S$ merupakan order maksimal, berlaku $\bar{r} \in R$ dan $\bar{s} \in S$. Apabila diperhatikan, $I \bar{v} W \subseteq V^{\prime} W \subseteq I$ dan $J \bar{w} V \subseteq W^{\prime} V \subseteq J$ (Lemma 1.2 [5]). Jadi, $\bar{v} W \subseteq O_{r}(I)=R$ dan $\bar{w} V \subseteq O_{r}(J)=S$. Akibatnya, berlaku $\bar{v} \in(R: W)_{l}=V$ dan $\bar{w} \in(S: V)_{l}=W$. Oleh karena itu, didapatkan $\bar{v} \in V$, dan $\bar{w} \in W$. Jadi, $\bar{t}=\left(\begin{array}{cc}\bar{r} & \bar{v} \\ \bar{w} & \bar{s}\end{array}\right) \in\left(\begin{array}{cc}R & V \\ W & S\end{array}\right)=T$ dan $O_{r}(A)=T$. Dengan cara ana$\log$ dapat pula ditunjukkan $O_{l}(A)=T$. Dengan demikian diperoleh $T$ merupakan order maksimal.

$(2) \Leftrightarrow(3)$ Jelas dari Lemma 2.12

$(2) \Rightarrow(4)$ Akan dibuktikan poin (ii) yaitu $(V W)_{v}=R$ yaitu $\left(R:(R: V W)_{l}\right)_{r}=R$. Dalam hal ini akan ditunjukkan $(R: V W)_{l}=R$. Apabila diperhatikan, $V W \subseteq R$. Jadi, berlaku $R \subseteq(R: V W)_{l}$. Diambil sebarang $q \in(R: V W)_{l}$ yang berarti $q V W \subseteq R$. Jadi, didapatkan $q V \subseteq(R: W)_{l}=V$. Akibatnya $q \in O_{l}(V)=R$. Terbukti, $(R: V W)_{l}=R$ dan $(V W)_{v}=R$. Apabila diperhatikan, ${ }_{v} V=(R$ : $\left.(R: V)_{r}\right)_{l}=(R: W)_{l}=V$ dan $V_{v}=\left(S:(S: V)_{l}\right)_{r}=(S: W)_{r}=V$ sehingga ${ }_{v} W=\left(R:(R: W)_{r}\right)_{l}=(R: V)_{l}=W$ dan $W_{v}=\left(S:(S: W)_{l}\right)_{r}=(S: V)_{r}=W$.

$(4) \Rightarrow(2)$ Apabila diperhatikan, $(V W)_{v}=R={ }_{v}(V W),(W V)_{v}=S={ }_{v}(W V)$ $V_{v}=V={ }_{v} V$ dan $W_{v}=W={ }_{v} W$. Berdasarkan Proposisi 3.1, didapatkan $V=$ 
$V_{v}=\left(\left(W^{-1} W\right)_{v} V\right)_{v} \subseteq\left(\left(W^{-1} W\right) V\right)_{v}=\left(W^{-1}(W V)_{v}\right)_{v}=\left(W^{-1}\right)_{v} \supseteq\left(W^{-1}\right)=$ $(R: W)_{l}$.

Jadi, diperoleh $(R: W)_{l}=V$. Analog untuk menunjukkan $V=(S: W)_{r}$. Dengan cara yang sama dapat ditunjukkan $(S: V)_{l}=W=(R: V)_{l}$.

Berikut akan diberikan contoh ring konteks Morita merupakan order maksimal dengan memanfaatkan Teorema 3.3 .

Contoh 3.4 Diberikan ring konteks Morita $T=\left(\begin{array}{cc}\mathbb{Z} & 2 \mathbb{Z} \\ \frac{1}{2} \mathbb{Z} & \mathbb{Z}\end{array}\right)$ di ring $Q(T)=$ $\left(\begin{array}{ll}\mathbb{Q} & \mathbb{Q} \\ \mathbb{Q} & \mathbb{Q}\end{array}\right)$. Diketahui bahwa $\mathbb{Z}$ merupakan order maksimal di ring $\mathbb{Q}$. Selanjutnya diperhatikan bahwa $\left(\mathbb{Z}: \frac{1}{2} \mathbb{Z}\right)_{l}=\left(\mathbb{Z}: \frac{1}{2} \mathbb{Z}\right)_{r}=2 \mathbb{Z}$ dan $(\mathbb{Z}: 2 \mathbb{Z})_{l}=(\mathbb{Z}: 2 \mathbb{Z})_{r}=\frac{1}{2} \mathbb{Z}$. Dengan demikian, diperoleh $T$ merupakan order maksimal.

Proposisi 3.5 [4] Misalkan $T=\left(\begin{array}{cc}R & V \\ W & S\end{array}\right)$ merupakan order maksimal di ring $Q(T)=\left(\begin{array}{cc}Q(R) & Q(V) \\ Q(W) & Q(S)\end{array}\right)$. Jika $A=\left(\begin{array}{cc}I & V^{\prime} \\ W^{\prime} & J\end{array}\right)$ merupakan suatu T-ideal di $Q(T) \operatorname{maka}(T: A)_{l}=\left(\begin{array}{cc}(R: I)_{l} & \left(R: W^{\prime}\right)_{l} \\ \left(S: V^{\prime}\right)_{l} & (S: J)_{l}\end{array}\right)$ dan $(T: A)_{r}=\left(\begin{array}{cc}(R: I)_{r} & \left(S: W^{\prime}\right)_{r} \\ \left(R: V^{\prime}\right)_{r} & (S: J)_{r}\end{array}\right)$.

Bukti. Diketahui $T$ merupakan order maksimal dan $A=\left(\begin{array}{cc}I & V^{\prime} \\ W^{\prime} & J\end{array}\right)$ merupakan suatu $T$-ideal di $Q(T)$. Akan ditunjukkan $(T: A)_{l}=\left(\begin{array}{cc}(R: I)_{l} & \left(R: W^{\prime}\right)_{l} \\ \left(S: V^{\prime}\right)_{l} & (S: J)_{l}\end{array}\right)$.

Diambil sebarang $\bar{t}=\left(\begin{array}{cc}\bar{r} & \bar{v} \\ \bar{w} & \bar{s}\end{array}\right) \in(T: A)_{l}$ yang berarti $\bar{t} A \subseteq T$ yaitu

$$
\left(\begin{array}{cc}
\bar{r} & \bar{v} \\
\bar{w} & \bar{s}
\end{array}\right)\left(\begin{array}{cc}
I & V^{\prime} \\
W^{\prime} & J
\end{array}\right) \subseteq\left(\begin{array}{cc}
R & V \\
W & S
\end{array}\right) .
$$

Jadi, diperoleh $\bar{r} I \subseteq R, \bar{v} W^{\prime} \subseteq R, \bar{w} V^{\prime} \subseteq S$, dan $\bar{r} J \subseteq S$. Jadi, $\bar{r} \in(R: I)_{l}, \bar{v} \in(R$ : $W)_{l}, \bar{w} \in\left(S: V^{\prime}\right)_{l}$, dan $\bar{s} \in(S: J)_{l}$. Dengan demikian diperoleh $\bar{t}=\left(\begin{array}{cc}\bar{r} & \bar{v} \\ \bar{w} & \bar{s}\end{array}\right) \in$ $\left(\begin{array}{cc}(R: I)_{l} & \left(R: W^{\prime}\right)_{l} \\ \left(S: V^{\prime}\right)_{l} & (S: J)_{l}\end{array}\right)$. Jadi, $(T: A)_{l} \subseteq\left(\begin{array}{cc}(R: I)_{l} & \left(R: W^{\prime}\right)_{l} \\ \left(S: V^{\prime}\right)_{l} & (S: J)_{l}\end{array}\right)$.

Sebaliknya, akan ditunjukkan $\left(\begin{array}{cc}(R: I)_{l} & \left(R: W^{\prime}\right)_{l} \\ \left(S: V^{\prime}\right)_{l} & (S: J)_{l}\end{array}\right) \subseteq(T: A)_{l}$. Apabila diperhatikan, $(R: I)_{l} I+\left(R: W^{\prime}\right)_{l} W^{\prime} \subseteq R$ dan $\left(S: V^{\prime}\right)_{l} V^{\prime}+(S: J)_{l} J \subseteq S$, berarti hanya perlu ditunjukkan $(R: I)_{l} V^{\prime}+\left(R: W^{\prime}\right)_{l} J \subseteq V$ dan $\left(S: V^{\prime}\right)_{l} I+(S:$ $J)_{l} W^{\prime} \subseteq W$. Akibatnya, diperoleh $(R: I)_{l} V^{\prime} W \subseteq(R: I)_{l} I \subseteq R$ dan $(R$ : 
$\left.W^{\prime}\right)_{l} J W \subseteq\left(R: W^{\prime}\right)_{l} W^{\prime} \subseteq R$ (Lemma $1.2[5]$ ). Menurut Teorema 3.3 didapatkan $(R: I)_{l} V^{\prime} \subseteq(R: W)_{l}=V$ dan $\left(R: W^{\prime}\right)_{l} J \subseteq(R: W)_{l}=V$. Hal ini mengakibatkan, $(R: I)_{l} V^{\prime}+\left(R: W^{\prime}\right)_{l} J \subseteq V$. Dengan cara yang sama dapat pula dapat ditunjukkan $\left(S: V^{\prime}\right)_{l} I+(S: J)_{l} W^{\prime} \subseteq W$.

Lemma 3.6 [4] Misalkan $T=\left(\begin{array}{cc}R & V \\ W & S\end{array}\right)$ merupakan order maksimal di ring $Q(T)=\left(\begin{array}{cc}Q(R) & Q(V) \\ Q(W) & Q(S)\end{array}\right)$. Jika $V^{\prime}$ merupakan $(R, S)$-modul fraksional maka $V_{v}^{\prime}=\left(V^{\prime} W V\right)_{v}=\left(\left(V^{\prime} W\right)_{v} V\right)_{v}$.

Bukti. Diketahui $T$ merupakan order maksinal di $Q(T)$ dan $V^{\prime}$ merupakan $(R, S)$ - modul fraksional. Akan ditunjukkan terlebih dahulu $V_{v}^{\prime}=\left(V^{\prime} W V\right)_{v}$ yaitu $(S$ : $\left.\left(S: V^{\prime}\right)_{l}\right)_{r}=\left(S:\left(S: V^{\prime} W V\right)_{l}\right)_{r}$. Dalam hal ini akan ditunjukkan bahwa $(S:$ $\left.V^{\prime}\right)_{l}=\left(S: V^{\prime} W V\right)_{l}$. Diketahui bahwa $V^{\prime} W V \subseteq V^{\prime} S=V^{\prime}$, yang berarti $(S$ : $\left.V^{\prime}\right)_{l} \subseteq\left(S: V^{\prime} W V\right)_{l}$. Sebaliknya diambil sebarang $\bar{w} \in\left(S: V^{\prime} W V\right)_{l}$, yang berarti $\bar{w} V^{\prime} W V \subseteq S$ dan $\bar{w} V^{\prime} W \subseteq(S: V)_{l}$. Dengan menggunakan fakta $T$ merupakan order maksimal, menurut Lemma 3.3 didapatkan $\bar{w} V^{\prime} W \subseteq(S: V)_{l}=W$. Jadi, $\bar{w} V^{\prime} \subseteq O_{l}(W)=S$ dan $\bar{w} \in\left(S: V^{\prime}\right)_{l}$. Akibatnya, $V_{v}^{\prime}=\left(V^{\prime} W V\right)_{v}$.

Selanjutnya akan dibuktikan $V_{v}^{\prime}=\left(\left(V^{\prime} W\right)_{v} V\right)_{v}$ yaitu $\left(S:\left(S: V^{\prime}\right)_{l}\right)_{r}=(S:$ $\left.\left(S:\left(V^{\prime} W\right)_{v} V\right)_{l}\right)_{r}$. Dalam hal ini akan ditunjukkan $\left(S: V^{\prime}\right)_{l}=\left(S:\left(V^{\prime} W\right)_{v} V\right)_{l}$ yaitu $\left(V^{\prime}\right)^{-1}=\left(S:\left(V^{\prime} W\right)_{v} V\right)_{l}$. Apabila diperhatikan $\left(V^{\prime}\right)^{-1} V^{\prime} W \subseteq S W=W$ dan $V\left(V^{\prime}\right)^{-1} V^{\prime} W \subseteq V W \subseteq R$. Jadi, $V\left(V^{\prime}\right)^{-1} \subseteq\left(R: V^{\prime} W\right)_{l}$ dan $V\left(V^{\prime}\right)^{-1}\left(V^{\prime} W\right)_{v}$ $\subseteq R$. Sehingga menurut Teorema 3.3 berlaku $\left(V^{\prime}\right)^{-1}\left(V^{\prime} W\right)_{v} \subseteq(R: V)_{r}=W$ dan $\left(V^{\prime}\right)^{-1}\left(V^{\prime} W\right)_{v} V \subseteq W V \subseteq S$. Hal ini mengakibatkan $\left(V^{\prime}\right)^{-1} \subseteq\left(S:\left(V^{\prime} W\right)_{v} V\right)_{l}$. Sebaliknya, diperhatikan bahwa $V^{\prime} W V \subseteq\left(V^{\prime} W\right)_{v} V$ dan $\left(S: V^{\prime}\right)_{l}=\left(V^{\prime}\right)^{-1}=$ $\left(S: V^{\prime} W V\right)_{l}$. Akibatnya, $\left(V^{\prime}\right)^{-1}=\left(S: V^{\prime} W V\right)_{l} \supseteq\left(S:\left(V^{\prime} W\right)_{v} V\right)_{l}$. Sehingga didapatkan $V_{v}^{\prime}=\left(\left(V^{\prime} W\right)_{v} V\right)_{v}$. Terbukti, $V_{v}^{\prime}=\left(V^{\prime} W V\right)_{v}=\left(\left(V^{\prime} W\right)_{v} V\right)_{v}$.

\section{RING KONTEKS MORITA SEBAGAI ORDER ASANO}

Pada bagian ini akan diberikan syarat perlu dan cukup bilamana suatu ring konteks Morita $T$ merupakan order Asano di ring $Q(T)$. Suatu ring Goldie prima disebut order Asano apabila setiap ideal tak nol di ring tersebut merupakan ideal invertibel yaitu untuk setiap $T$-ideal $A$ di $Q(T)$ terdapat $T$-ideal $A^{-1}$ di $Q(T)$ sedemikian sehingga $A A^{-1}=A^{-1} A=T$. [5]. Order $T$ Merupakan order Asano jika dan hanya jika $T$ merupakan order maksimal dan setiap $T$-ideal di $Q(T)$ merupakan $v$-ideal (Proposition 5.2.6, 4]).

Berikut akan diberikan sifat yang berlaku pada ring konteks Morita 


$$
T=\left(\begin{array}{cc}
R & V \\
W & S
\end{array}\right)
$$

apabila ring $R$ merupakan order Asano di $Q(R)$ dan $\operatorname{ring} S$ merupakan order Asano di $Q(S)$.

Lemma 4.1 4] Diberikan order $T=\left(\begin{array}{cc}R & V \\ W & S\end{array}\right)$ di ring $Q(T)=\left(\begin{array}{cc}Q(R) & Q(V) \\ Q(W) & Q(S)\end{array}\right)$. Jika ring $R$ merupakan order Asano di $Q(R)$ dan ring $S$ merupakan order Asano di $Q(S)$ maka

(1) $\left(V^{\prime}\right)^{-1} V^{\prime}=S$ dan $V^{\prime}\left(V^{\prime}\right)^{-1}=R$ untuk setiap $(R, S)$-modul fraksional $V^{\prime}$ di $Q(V)$,

(2) $\left(W^{\prime}\right)^{-1} W^{\prime}=R$ dan $W^{\prime}\left(W^{\prime}\right)^{-1}=S$ untuk setiap $(S, R)$-modul fraksional $W^{\prime}$ di $Q(V)$.

Bukti. Diketahui $R$ merupakan order Asano di $Q(R)$ dan $\operatorname{ring} S$ merupakan order Asano di $Q(S)$.

(1) Akan dibuktikan $\left(V^{\prime}\right)^{-1} V^{\prime}=S$ dan $V^{\prime}\left(V^{\prime}\right)^{-1}=R$ untuk setiap $(R, S-$ modul fraksional $V^{\prime}$ di $Q(V)$. Diambil sebarang $(R, S)$-modul fraksional $V^{\prime}$ di $Q(V)$. Diketahui bahwa ring $R$ merupakan order Asano di $Q(R)$ dan $S$ merupakan order Asano di $Q(S)$. Tulis $J=\left(V^{\prime}\right)^{-1} V^{\prime}$. Andaikan $J \subset$ $R$. Karena $S$ merupakan order Asano, berlaku $J^{-1}\left(V^{\prime}\right)^{-1} V^{\prime}=J^{-1} J=$ S. Jadi, $J^{-1}\left(V^{\prime}\right)^{-1} \subseteq\left(S: V^{\prime}\right)_{l}=\left(V^{\prime}\right)^{-1}$ dan $J^{-1} \subseteq O_{l}\left(V^{\prime}\right)^{-1}=S$. Akibatnya, $J^{-1} J \subseteq S J=J \subset R$. Kontradiksi dengan $J^{-1} J=S$. Oleh karena itu, haruslah $J=\left(V^{\prime}\right)^{-1} V^{\prime}=S$. Dengan cara yang sama dapat pula ditunjukkan $V^{\prime}\left(V^{\prime}\right)^{-1}=R$.

(2) Akan dibuktikan $\left(W^{\prime}\right)^{-1} W^{\prime}=R$ dan $W^{\prime}\left(W^{\prime}\right)^{-1}=S$ untuk setiap $W^{\prime}$ yang merupakan $(S, R)$-modul fraksional di $Q(W)$. Tulis $I=\left(W^{\prime}\right)^{-1} W^{\prime}$. Andaikan $I \subset R$. Karena $R$ merupakan order Asano, berlaku $I^{-1}\left(W^{\prime}\right)^{-1} W^{\prime}$ $=I^{-1} I=R$. Jadi, $I^{-1}\left(W^{\prime}\right)^{-1} \subseteq\left(R: W^{\prime}\right)_{l}=\left(W^{\prime}\right)^{-1}$ dan $I^{-1} \subseteq$ $O_{l}\left(V^{\prime}\right)^{-1}=S$. Akibatnya, $I^{-1} I \subseteq R I=I \subset R$. Kontradiksi dengan $I^{-1} I=R$. Oleh karena itu, haruslah $I=\left(W^{\prime}\right)^{-1} W^{\prime}=R$. Dengan cara yang sama dapat pula ditunjukkan $W^{\prime}\left(S^{\prime}\right)^{-1}=R$.

Lemma di atas kemudian memotivasi definisi berikut [4.

Definisi 4.2 Diberikan order $T=\left(\begin{array}{cc}R & V \\ W & S\end{array}\right)$ di ring $Q(T)=\left(\begin{array}{cc}Q(R) & Q(V) \\ Q(W) & Q(S)\end{array}\right)$.

(1) $V$ disebut $(R, S)-$ modul A sano apabila $\left(V^{\prime}\right)^{-1} V^{\prime}=S$ dan $V^{\prime}\left(V^{\prime}\right)^{-1}=R$ untuk setiap $V^{\prime}$ yang merupakan $(R, S)$-modul fraksional di $Q(V)$, 
(2) $W$ disebut $(S, R)-$ modul Asano apabila $\left(W^{\prime}\right)^{-1} W^{\prime}=R$ dan $W^{\prime}\left(W^{\prime}\right)^{-1}=$ $S$ untuk setiap $W^{\prime}$ yang merupakan $(S, R)$-modul fraksional di $Q(W)$.

Proposisi 4.3 4] Diberikan order $T$ di ring $Q(T)$. Jika $V W=R$ dan $W V=S$ maka terdapat korespondensi satu-satu antara himpunan semua $R$-ideal di $Q(R)$ dan himpunan semua $(R, S)$-modul fraksional di $Q(V)$.

Bukti. Misalkan $\mathcal{J}(V)$ merupakan himpunan semua $(R, S)$-modul fraksional di $Q(V)$ dan $\mathcal{J}(R)$ merupakan himpunan semua $R$-ideal di $Q(R)$. Selanjutnya didefinisikan fungsi

$$
f: \mathcal{J}(V) \rightarrow \mathcal{J}(R)
$$

dengan $f\left(V^{\prime}\right)=V^{\prime} W$ untuk setiap $V^{\prime} \in \mathcal{J}(V)$. Diambil sebarang $V^{\prime}, V^{\prime \prime} \in \mathcal{J}(V)$ dengan $f\left(V^{\prime}\right)=f\left(V^{\prime \prime}\right)$ yaitu $V^{\prime} W=V^{\prime \prime} W$. Akibatnya, diperoleh $V^{\prime}=V^{\prime} W V=$ $V^{\prime \prime} W V=V^{\prime \prime} S=V^{\prime \prime}$. Selanjutnya didefinisikan fungsi

$$
g: \mathcal{J}(R) \rightarrow \mathcal{J}(V)
$$

dengan $g(I)=I V$ untuk setiap $I \in D(R)$ maka diperoleh $f \circ g(I)=f(g(I))=$ $f(I V)=I V W=I$. Dengan demikian $f$ merupakan fungsi bijektif. Terbukti, terdapat korespondensi satu-satu antara $\mathcal{J}(R)$ dan $\mathcal{J}(V)$.

Teorema 4.4 4] Diberikan order $T=\left(\begin{array}{cc}R & V \\ W & S\end{array}\right)$ di ring $Q(T)=\left(\begin{array}{cc}Q(R) & Q(V) \\ Q(W) & Q(S)\end{array}\right)$. Pernyataan-pernyataan berikut ekuivalen.

(1) Ring $T$ merupakan order Asano di ring $Q(T)$.

(2) (a) ring $R$ merupakan order Asano di $Q(R)$ dan ring $S$ merupakan order Asano di $Q(S)$;

(b) $V W=R$ dan $W V=S$.

(3) (a) Modul $V$ disebut $(R, S)-$ modul Asano di $Q(V)$ dan Modul $W$ disebut $(S, R)-$ modul Asano di $Q(W)$;

(b) $V W=R$ dan $W V=S$.

Bukti. (1) $\Rightarrow(2)$ Diketahui bahwa ring $T$ merupakan order Asano di ring $Q(T)$. Dari sini, diperoleh ring $T$ merupakan order maksimal di ring $Q(T)$. Menurut Teorema 3.3 , didapatkan ring $R$ merupakan order maksimal di $Q(R)$ dan ring $S$ merupakan order maksimal di $Q(S)$. Selanjutnya diambil sebarang $R$-ideal integral di $Q(R)$. Dibentuk suatu $T$-ideal integral di $Q(T)$ yaitu $A=\left(\begin{array}{cc}I & I V \\ W I & W I V\end{array}\right)$. Mengingat $T$ merupakan order Asano, haruslah

$$
A=A_{v}=\left(\begin{array}{cc}
I_{v} & (I V)_{v} \\
(W I)_{v} & (W I V)_{v}
\end{array}\right)
$$


Jadi, $I_{v}=I$ yaitu $I$ merupakan $v$-ideal di $\operatorname{ring} Q(R)$. Dengan kata lain, $R$ merupakan order Asano di ring $Q(R)$. Kemudian diambil sebarang $S$-ideal integral di $Q(S)$. Dengan cara yang sama dapat ditunjukkan $S$ merupakan order Asano di $\operatorname{ring} Q(S)$.

Selanjutnya akan ditunjukkan $V W=R$ dan $W V=S$. Jelas bahwa $V W \subseteq R$. Tulis $I=V W$. Andaikan $I \subset R$. Karena $R$ merupakan order Asano, didapatkan $I^{-1} I=I^{-1} V W=R$. Menurut Teorema 3.3, berlaku $I^{-1} V \subseteq(R: W)_{l}=V$. Jadi, $I^{-1} \subseteq O_{l}(V)=R$. Hal ini mengakibatkan $I^{-1} I \subseteq R I=I \subset R$. Hal ini mengakibatkan kontradiksi dengan $I^{-1} I=R$. Oleh karena itu, haruslah $I=$ $V W=R$. Dengan cara yang sama dapat ditunjukkan pula $W V=S$.

$(2) \Rightarrow(3)$ Jelas dari Lemma 4.1 .

$(3) \Rightarrow(1)$ Apabila diperhatikan $(R: W)_{l}=V W(R: W)_{l} \subseteq V$ dan $(S: W)_{r}=(R$ : $W)_{l} W V \subseteq V$. Jadi, diperoleh $(R: W)_{l}=V=(S: W)_{r}$. Dengan cara yang sama dapat pula ditunjukkan $(R: W)_{l}=V=(S: W)_{r}$ dan $(R: V)_{r}=W=(S: V)_{l}$.

Diambil sebarang $R$-ideal integral di $Q(R)$. Berdasarkan Proposisi 4.3 terdapat suatu $(R, S)$-modul frkaksional $V^{\prime}$ di $Q(V)$ sedemikian sehingga $I=V^{\prime} W$. Apabila diperhatikan $V\left(V^{\prime}\right)^{-1}$ merupakan $R$-ideal di $Q(R)$. Karena $V$ merupakan $(R, S)$-modul Asano di $Q(V)$, didapatkan $I\left(V\left(V^{\prime}\right)^{-1}\right)=V^{\prime} W\left(V\left(V^{\prime}\right)^{-1}\right)=$ $V^{\prime}\left(V^{\prime}\right)^{-1}=R$, maka berlaku $\left(V\left(V^{\prime}\right)^{-1}\right) I=\left(V\left(V^{\prime}\right)^{-1}\right) V^{\prime} W=V S W=V W=R$. Jadi, $I$ merupakan ideal invertibel. Dengan kata lain, $R$ merupakan order Asano. Dengan cara yang sama dapat pula ditunjukkan ring $S$ merupakan order Asano di ring $Q(S)$. Akibatnya, diperoleh $R$ merupakan order maksimal di $Q(R)$ dan ring $S$ merupakan order maksimal di $Q(S)$. Apabila diperhatikan $(R: W)_{l}=V=(S$ : $W)_{r}$ dan $(R: V)_{r}=W=(S: V)_{l}$. Menurut Teorema 3.3. $T$ merupakan order maksimal.

Diambil sebarang $T$-ideal integral $A=\left(\begin{array}{cc}I & V^{\prime} \\ W^{\prime} & J\end{array}\right)$ di $Q(T)$ Dengan menggunakan fakta bahwa $R$ merupakan order Asano dan $S$ merupakan order Asano di ring $Q(S)$, berlaku $I_{v}=I$ dan $J_{v}=J$. Lebih lanjut akan ditunjukkan bahwa $V_{v}^{\prime}=V^{\prime}$ dan $W_{v}^{\prime}=W^{\prime}$. Akan ditunjukkan terlebih dahulu $V^{\prime}=I V$. Apabila diperhatikan, $I V \subseteq V^{\prime}$ dan $V^{\prime} W \subseteq I$ (Lemma $1.2[5]$ ). Oleh karena itu, berlaku $I V \subseteq V^{\prime}=$ $V^{\prime} S=V^{\prime} W V=I V$. Jadi, $V^{\prime}=I V$. Diketahui bahwa $I=I V W \subseteq(I V)_{v} W \subseteq$ $\left((I V)_{v} W\right)_{v}=(I V W)_{v}=I_{v}=I$ sehingga $I V=(I V)_{v} W V=(I V)_{v} S=(I V)_{v}$. Jadi, diperoleh $V^{\prime}=I V=(I V)_{v}=V_{v}^{\prime}$. Dengan cara yang sama dapat ditunjukkan pula bahwa $W^{\prime}=W I$. Menurut lemma 2.18, didapatkan $I=V W I \subseteq V(W I)_{v} \subseteq$ $\left(V(W I)_{v}\right)_{v}=(V W I)_{v}=I_{v}=I$. Oleh karena itu, didapatkan $I=V(W I)_{v}$ dan $W I=W V(W I)_{v}=S(W I)_{v}=(W I)_{v}$. Sehingga dapat disimpulkan bahwa 
$W^{\prime}=W I=(W I)_{v}=W_{v}^{\prime}$. Jadi, diperoleh

$$
A=\left(\begin{array}{cc}
I & V^{\prime} \\
W^{\prime} & J
\end{array}\right)=\left(\begin{array}{cc}
I_{v} & V_{v}^{\prime} \\
W_{v}^{\prime} & J_{v}
\end{array}\right)=A_{v}
$$

Dengan demikian diperoleh $T$ merupakan order maksimal di $Q(T)$ dan setiap $T$-ideal integral di $Q(T)$ merupakan $v$-ideal. Terbukti, $T$ merupakan order Asano (Proposition 5.2.6, 4]).

\section{PENUTUP}

Adapun kesimpulan dari penulisan ini yaitu syarat perlu dan cukup untuk membuktikan suatu ring konteks Morita sebagai order maksimal dan order Asano sebagai berikut.

(1) Suatu ring konteks Morita $T=\left(\begin{array}{cc}R & V \\ W & S\end{array}\right)$ di $\operatorname{ring} Q(T)=\left(\begin{array}{cc}Q(R) & Q(V) \\ Q(W) & Q(S)\end{array}\right)$ merupakan order maksimal jika dan hanya jika dengan ring $R$ merupakan order maksimal di $Q(R)$ dan ring $S$ merupakan order maksimal di $Q(S)$ serta $(R: V)_{r}=(S: V)_{l}=W$ dan $(R: W)_{l}=(S: W)_{r}=V$.

(2) Suatu ring konteks Morita $T=\left(\begin{array}{cc}R & V \\ W & S\end{array}\right)$ di $\operatorname{ring} Q(T)=\left(\begin{array}{cc}Q(R) & Q(V) \\ Q(W) & Q(S)\end{array}\right)$ merupakan order Asano jika dan hanya jika ring $R$ merupakan order Asano di $Q(R)$ dan ring $S$ merupakan order Asano di $Q(S)$ serta $V W=R$ dan $W V=S$.

Adapun saran dari penulisan ini yaitu untuk penelitian kedepannya, diharapkan dapat diberikan syarat perlu dan cukup $T$ merupakan order Dedekind, order G-Dedekind Prima dan order Krull.

Ucapan Terima Kasih. Penelitian ini didukung oleh Kementrian Riset, Teknologi, dan Pendidikan Tinggi Republik Indonesia melalui Hibah Penelilitian Tesis Magister berdasarkan Surat Keputusan No. 8/E1/KP.PTNBH/2019 dan Perjanjian Kontrak No.2864/UNI/DITLIT/DIT-LIT/LT/2019. Penulis mengucapkan terima kasih kepada Professor Hidetoshi Marubayashi dari Naruto University of Education, Jepang yang telah memberi kuliah dan diskusi serta menjawab beberapa pertanyaan terkait topik penelitian ini. Penulis juga mengucapkan terima kasih kepada para reviewer Jurnal Matematika Thales, Departemen Matematika, Universitas Gadjah Mada atas saran dan komentar yang diberikan. 


\section{REFERENSI}

[1] Chatters, A. W. dan Hajarnavis, C. R, Rings with Chain Conditions, Research Notes in Mathematics, Vol. 44, Pitman Advanced Publishing Program, Boston, 1980.

[2] Clase, M. V., Semiprime Goldie Generlized Matrix Rings, Canad. Math. Bull 38(1995), 174-176.

[3] Marubayashi, H. dan van Oystaeyen, F, Prime Divisors and Noncommutative Valuation Theory, Springer, New York, 2001.

[4] Marubayashi, H. Saraç, B. Akalan, E., dan Aydoğdu, P., Rings of Morita Context Which Are Maximal Orders, J.Algebra 26(2015), 1-13.

[5] Marubayashi, H. Zhang, Y. dan Yang, P., On The Ring of Morita Context Which Are Some Well-Known Orders, Comm. Algebra 26(5) (1998), 1429-1442.

[6] McConnell, J. C. dan Robson, J. C., Noncommutative Noetherian Rings, Wiley, New York, 2001.

[7] Nicholson, J. W. K. dan Watters, F. J., Normal Radicals and Normal Classes of Rings, J.Algebra 59 (1979), 5-15.

\section{Novita DahoKlorY* (Penulis Korespondensi)}

Universitas Gadjah Mada, Indonesia

novitadahoklory93@gmail.com

INDAH EMILIA WIJAYANTI

Departemen Matematika Fakultas MIPA, Universitas Gadjah Mada, Indonesia ind_wijayanti@ugm.ac.id

\section{Sutopo}

Departemen Matematika Fakultas MIPA, Universitas Gadjah Mada, Indonesia sutopo_mipa@ugm.ac.id 